Dennis L. Newell ${ }^{1}$, J. William Carey², Scott N. Backhaus ${ }^{3}$, and Peter Lichtner ${ }^{4}$

\title{
Experimental Study of Gravitational Mixing of Supercritical $\mathrm{CO}_{2}$
}

4

5

$6 \quad{ }^{1}$ Department of Geology, Utah State University, Logan, UT 84322

7 2Earth \& Environmental Sciences, Los Alamos National Laboratory, Los Alamos, NM 87545

$8 \quad{ }^{3}$ Materials Physics and Applications, Los Alamos National Laboratory, Los Alamos, NM 87545

$9 \quad{ }^{4}$ OFM Research, Redmond, WA 98053

10

11

12

13
Corresponding author: Dennis L. Newell, 435-797-0479, dennis.newell@usu.edu 


\section{Abstract}

$15 \mathrm{CO}_{2}$ injection into saline aquifers for sequestration will initially result in buoyant supercritical

$16(\mathrm{sc}) \mathrm{CO}_{2}$ trapped beneath the caprock seal. During this period, there is risk of $\mathrm{CO}_{2}$ migration out

17 of the reservoir along wellbore defects or fracture zones. Dissolution of the $\mathrm{scCO}_{2}$ plume into

18 brine results in solubility trapping and reduces this risk, but based on diffusion alone, this

19 mechanism could take thousands of years. Gravitational (density-induced) mixing of $\mathrm{CO}_{2}$ -

20 saturated brine is shown to significantly accelerate this process in computational studies, but few

21 experimental efforts have confirmed the phenomenon. Here, constant-pressure, 3-dimensional

22 bench-scale experiments used the mass of added water to quantify the mass transfer of $\mathrm{scCO}_{2}$

23 into water-saturated porous media at $40-90^{\circ} \mathrm{C}$ and $20 \mathrm{MPa}$, with Rayleigh numbers from 2093 to

24 16256. Experiments exhibit a period of 7-35X enhancement in mass transfer rates over diffusion, 25 interpreted as gravitational mixing. Convective $\mathrm{CO}_{2}$ flux ranges from $1.6 \times 10^{-2}$ to $4.8 \times 10^{-3} \mathrm{~mol} \cdot \mathrm{s}^{-}$ $26{ }^{1} \mathrm{~m}^{-2}$ in the experiments. Results are used to benchmark a computational model using

27 PFLOTRAN. Experiments show an early diffusive onset period that is shorter with rates much

28 higher than predicted by models and observed in analog experiments. Both experiments and 29 models show convective mixing periods and similar overall rates of $\mathrm{CO}_{2}$ mass transfer.

31 Keywords: Convective $\mathrm{CO}_{2}$ mixing; supercritical $\mathrm{CO}_{2}$-water experiments; $\mathrm{CO}_{2}$ sequestration; 32 PFLOTRAN 


\subsection{Introduction}

Risks associated with the geologic sequestration of $\mathrm{CO}_{2}$ are dependent on the mobility of

36 the buoyant supercritical plume in the subsurface. There are four primary mechanisms for

37 immobilizing $\mathrm{CO}_{2}$ and reducing risk: dissolution of $\mathrm{CO}_{2}$ into brine (solubility trapping), reaction

38 of dissolved $\mathrm{CO}_{2}$ with minerals to form bicarbonate ions (ionic trapping), precipitation of

39 carbonate minerals (mineral trapping), and isolation of discrete $\mathrm{CO}_{2}$ blobs by capillary forces

40 (capillary trapping) (e.g., Metz et al., 2005). In the absence of these mechanisms, supercritical

41 (sc) $\mathrm{CO}_{2}$ must be confined by stratigraphic barriers (i.e., impermeable caprock). Although these

42 barriers are known to have performed over millions of years as observed at oil and natural gas

43 reservoirs, uncertainty exists because the plume is mobile and capable of leaking through defects

44 in the caprock including wells that penetrate the storage reservoir (e.g., caprock leakage at

45 Springerville-St. Johns Dome, Arizona and Crystal Geyser, Arizona; (Moore et al., 2005;

46 Shipton et al., 2005; Kampman et al., 2012; Han et al., 2013; Keating et al., 2014).

47 There has been considerable discussion, theoretical analysis and computational

48 simulation of the potential importance of gravitational mixing in enhancing the rate and quantity

49 of $\mathrm{CO}_{2}$ immobilized by solubility trapping (e.g., Ennis-King et al., 2005; Riaz et al., 2006; Xu et

50 al., 2006; Ennis-King and Paterson, 2007; Hassanzadeh et al., 2007; Rapaka et al., 2008; Rapaka

51 et al., 2009; Pau et al., 2010; Jha et al., 2011; MacMinn et al., 2011). This work has illuminated

52 the relationship between reservoir properties (principally depth, permeability, and anisotropy)

53 and the onset of gravitational mixing. Conceptually, a $\mathrm{scCO}_{2}$ plume trapped between a caprock

54 seal and underlying brine-saturated reservoir will first diffuse into the brine, building up a thin

55 layer that is $0.1-1 \%$ denser, depending on pressure and temperature (Kneafsey and Pruess,

56 2010). After some "onset time", this layer becomes gravitationally unstable and begins to 
57 descend through the porous media as fingers of $\mathrm{CO}_{2}$-saturated brine. These studies highlight that

58 for most reservoirs, once a gravitational instability is established, density driven convection and

59 mixing dramatically enhances $\mathrm{CO}_{2}$ mass transfer to brine compared to diffusion alone.

60 However, the importance and duration of an initial onset time to establish the instability is

61 debated. Onset times can range from days to thousands of years depending on features such as

62 permeability anisotropy, geochemical reactions and reservoir heterogeneities.

There has been relatively less experimental work on gravitational instabilities and mixing

64 relevant to the $\mathrm{CO}_{2}$ problem. Laboratory experiments using analog fluids with similar density

65 and viscosity contrasts to $\mathrm{scCO}_{2}$ and water include: Neufeld et al. (2010) who studied methanol-

66 ethylene glycol mixtures with water in thin plates filled with porous media, and Backhaus et al.

67 (2011) who used the propylene glycol (PPG)-water system in Hele-Shaw cells. These studies

68 have helped visualize and quantify the establishment of a gravitational instability and subsequent

69 convective mixing of dense fingers. Through classical dimensionless scaling, these studies have

70 shown significant (several 100X) convective mass transfer rate enhancements over diffusion

71 alone. Several studies addressed gravitational mixing using the $\mathrm{CO}_{2}$-water system, rather than

72 analog fluids. Kneafsey and Pruess (2010) and Faisal et al., (2015) introduced gas phase $\mathrm{CO}_{2}$ at

73 ambient temperature and pressure into the top of water filled vertical Hele-Shaw cells to observe

74 gravitational instabilities and mixing. These experiments combined visual and analytical

75 protocols for quantifying $\mathrm{CO}_{2}$ mass transfer in a Hele-Shaw geometry to allow for improved

76 validation of numerical simulation. Hele-Shaw experiments allow direct visualization of the

77 development of density fingers and precise determination of when they reach the base of the cell.

78 However, they are 2D and limited to ambient conditions. Three-dimensional mixing experiments

79 using cylindrical pressure vessels allow for higher pressure and temperature conditions and 
80 inclusion of a porous media, but lack the benefit of direct visualization of the fingers.

81 Experiments using pressure vessels have employed a constant volume approach to measure the

82 mass transfer of $\mathrm{CO}_{2}$ to water by observing the pressure decay. For example, experiments have

83 measured $\mathrm{CO}_{2}$ mass transfer to water at $25^{\circ} \mathrm{C}$ and $1-5 \mathrm{MPa}$ (Farajzadeh et al., 2009), to water-

84 saturated porous media at $25^{\circ} \mathrm{C}$ and $2-6 \mathrm{MPa}$ (Moghaddam et al., 2012), and to water and

85 brine (up to $20 \%$ salinity) saturated porous media at $38^{\circ} \mathrm{C}$ and $3.45 \mathrm{MPa}$ (Mojtaba et al., 2014;

86 Moghaddam et al., 2015). Although these experiments are informative to the general behavior of

$873 \mathrm{D}$ density driven mixing, these $\mathrm{CO}_{2}$-water experiments were not conducted at relevant reservoir

88 conditions so the $\mathrm{CO}_{2}$ phase (gas and liquid vs. supercritical), fluid densities, viscosities and the

89 solubility of $\mathrm{CO}_{2}$ in water are not analogous.

90 In this study, we have conducted bench-scale supercritical $\mathrm{CO}_{2}$-water mass transfer

91 experiments into homogenous saturated porous media at pressures and temperatures relevant to

92 geologic carbon sequestration. We compare several experimental approaches (e.g., constant

93 volume and constant pressure) and provide quantitative results from the most effective method

94 for simulating the scenario of a buoyant $\mathrm{scCO}_{2}$ plume in contact with a saturated porous media.

95 The results are cast both as actual mass transfer rates and using dimensional scaling for

96 comparison to analog experiments (e.g., Backhaus et al., 2011). These results are also used to

97 benchmark a computational model using PFLOTRAN (Lu and Lichtner, 2007; Lichtner and

98 Hammond, 2012; Lichtner et al., 2017). In this study we focus on understanding these

99 phenomenon in a homogeneous and isotropic porous media, but we recognize that real systems

100 will be heterogeneous. The goal is to provide a scalable experimental basis and modeling basis

101 for determining the significance of convective mixing in target geologic reservoirs for carbon 
102 sequestration, providing a foundation for studies to consider these processes in a heterogeneous

103 reservoir.

$104 \quad 2.0 \quad$ Methods

$105 \quad 2.1 \quad$ Experimental Methods and Materials

106 To identify the most robust method for quantifying the mass transfer of $\mathrm{scCO}_{2}$ to water in

107 a porous media, several different techniques were employed. The goal was to develop an

108 experimental approach that placed $\mathrm{scCO}_{2}$ in sharp contact above water-saturated porous media in

109 order to capture both diffusive and convective mixing periods as demonstrated by analog and

110 modeling studies. For completeness and to provide a guide to experimentalists, we describe each

111 of the methods and their advantages and disadvantages. Challenges involved minimizing the

112 amount of trapped $\mathrm{CO}_{2}$ below the water $-\mathrm{scCO}_{2}$ interface within the porous media prior to the

113 start of the dissolution experiment, and placing the $\mathrm{CO}_{2}$ in sharp contact with the water-saturated

114 media quickly.

\section{2.1.1 Constant volume: $\mathrm{CO}_{2}$ injection into water-saturated porous media}

116 In this approach, the change in pressure in a constant-volume reactor is recorded as the

117 introduced $\mathrm{CO}_{2}$ dissolves into water. A stainless-steel high-pressure reactor was packed (tapped

118 and shaken) with monodispersed $500 \mu \mathrm{m}$ diameter spherical soda-lime glass beads, and vacuum

119 loaded with water to ensure single-phase saturation, and heated to $40^{\circ} \mathrm{C}$ (Figure 1). The pressure

120 vessel was equipped with an inlet and exit port and to each port a high-pressure syringe pump

121 (ISCO pump) was attached. One pump was filled with water to pressurize the reactor to $20 \mathrm{MPa}$

122 (200 bars). The second pump was filled with liquid $\mathrm{CO}_{2}$ and compressed to $20 \mathrm{MPa}$. High

123 pressure $\mathrm{CO}_{2}$ was injected into the reactor through the porous media where it displaced water

124 and accumulated in the upper region of the vessel. Once in the heated reactor, the $\mathrm{CO}_{2}$ is in the 
125 supercritical state. The water pump maintained a constant pressure of $20 \mathrm{MPa}$ by removing water

126 from the reactor. Once the desired mass of $\mathrm{CO}_{2}$ was injected, the reactor was isolated from the

127 pumps and the subsequent pressure history was recorded.

128 During these experiments, the pressure dropped as $\mathrm{CO}_{2}$ dissolved into water; however,

129 analysis of the pressure decay curves for comparison to other modeling and analog experiments

130 (e.g., Backhaus et al., 2011) proved difficult. First, converting the pressure drop versus time

131 record to the mass of $\mathrm{CO}_{2}$ dissolved is complicated because as pressure drops, the properties of

$132 \mathrm{CO}_{2}$, including its solubility, change. More significantly, however, is that the injection method

133 results in an unknown interface area between the $\mathrm{CO}_{2}$ and water. As shown by Lenormand et al.,

134 (1988), the immiscible displacement resulting from the injection of the lower viscosity $\mathrm{CO}_{2}$ into

135 the higher viscosity water-saturated porous media likely resulted in viscous or capillary

136 fingering, depending on the capillary number. This resulted in an unknown and high initial

137 surface areas between water and $\mathrm{CO}_{2}$, not the desired sharp contact between the fluids. An

138 additional uncertainty is the impact on interfacial tension as $\mathrm{CO}_{2}$ dissolves into water during

139 fluid displacement. This method was abandoned due to the uncertainty in the post-injection fluid

140 configuration.

141 2.1.2 Constant pressure: water injection into $\mathrm{CO}_{2}$-saturated porous media

142 To overcome the problems of 1) quantifying $\mathrm{CO}_{2}$ dissolution from pressure decay curves,

143 2) the unknown $\mathrm{CO}_{2}$-water surface area due to fingering during $\mathrm{CO}_{2}$ invasion, an apparatus was

144 developed to allow for water injection into the base of a reactor held at constant pressure and

145 temperature. Injecting the higher viscosity fluid (water) into lower viscosity $\mathrm{scCO}_{2}$ should result

146 in a more stable displacement front (Lenormand et al., 1988), with a sharper interface and known

147 surface area. 
Figure 2A schematically shows the experimental apparatus used for these experiments.

149 A cylindrical stainless-steel reaction vessel (HIP GC13 series) was filled with monodispersed

$150500 \mu \mathrm{m}$ diameter spherical soda-lime glass beads. The reaction vessel has 3 access ports: one is

151 used for a thermocouple, one opens to the top of the vessel, and the last is connected to the

152 bottom of the cell through a small diameter stainless-steel tube. The internal dimensions of the

153 vessel were $24.6 \mathrm{~cm}$ high by $6.3 \mathrm{~cm}$ in diameter, with a cross-sectional area of $30.9 \mathrm{~cm}^{2}$, and

154 volume of $\sim 800 \mathrm{~cm}^{3}$. Beads were poured into the vessel while tapping and shaking the vessel for

155 a close-random pack (RCP) arrangement of beads with a porosity between 0.359 and 0.375

156 (Dullien, 1992; Torquato et al., 2000). To confirm the porosity, the mass of beads added to the

157 vessel was measured, and the solid fraction was determined by using the density of the soda lime

158 glass beads $\left(2.4 \mathrm{~g} / \mathrm{cm}^{3}\right)$. For these experiments, a RCP with an average porosity of 0.367 was

159 achieved. The bead-packed vessel was placed into a vertically oriented rocking-autoclave

160 furnace.

161 The reactor was first heated to the desired temperature and evacuated with a vacuum

162 pump. A high-pressure ISCO syringe pump was used to fill and pressurize the heated reactor 163 with $\mathrm{scCO}_{2}$. The target pressure for these experiments was $20 \mathrm{MPa}$. To prepare for water 164 injection the $\mathrm{CO}_{2}$ pump was set at constant pressure mode at $20 \mathrm{MPa}$. Water was then injected 165 with a separate ISCO pump into the base of the porous media. As water was injected, $\mathrm{CO}_{2}$ was 166 removed from the top of the vessel to maintain a constant pressure of $20 \mathrm{MPa}$. Once the desired 167 volume of water was injected, the $\mathrm{CO}_{2}$ pump was isolated and the water injection pump was 168 switched to constant pressure mode at $20 \mathrm{MPa}$. As $\mathrm{scCO}_{2}$ dissolved into the water, the water 169 ISCO pump added water to the base of the vessel to maintain constant pressure. Pressure, 170 temperature and the volume of water added to the vessel were logged at a frequency of one 
171 second. The mass of water added was used as a proxy for the mass of $\mathrm{CO}_{2}$ dissolved as 172 discussed later.

173 Initial data reduction of these experiments indicated unexpectedly high amounts of $\mathrm{scCO}_{2}$

174 becoming dissolved shortly after injection of water. To evaluate the nature of the $\mathrm{scCO}_{2}-\mathrm{water}$ 175 interface, an analog injection test was conducted. Identical monodispersed glass beads were 176 packed between two plexiglass plates to create a pseudo two-dimensional cell. The glass bead 177 pack was saturated with a low viscosity silicon oil to represent " $\mathrm{scCO}_{2}$ ". Water was simulated 178 with a dyed glycerol-water solution prepared to reproduce the viscosity contrast of the $\mathrm{scCO}_{2}$ 179 water system (Segur and Oberstar, 1951). The glycerol-water mix was injected into the base of 180 the cell, displacing the oil. The injection rate was scaled (slowed) to the absolute viscosity 181 difference between water in the $\mathrm{scCO}_{2}$-water system and the glycerol mixture in the analog oil 182 glycerol solution system to simulate the same capillary number and viscosity ratio. The analog 183 fluids are immiscible in contrast to the slight miscibility of the $\mathrm{scCO}_{2}$-water system; however, 184 this is an insignificant factor for the short duration and purposes of this experiment.

185 The displacement front in this analog system was stable with only minor undulations in 186 the interface between the fluids. The evolution of the interface and displacement history was 187 carefully photographed to calculate the volume of oil displaced versus the volume of glycerol 188 solution injected. Based on this analysis, approximately 5\% trapped oil remained in the glycerol189 flushed region (trapped in pores and pore throats). Although 5\% appears to be a small 190 percentage, given the relatively low solubility of $\mathrm{CO}_{2}$ in water and the high surface area of the 191 trapped phase, this equates to the potential for substantial transfer of $\mathrm{CO}_{2}$ into water that does not 192 occur across the interface between the bulk fluids. Thus, if the $\mathrm{CO}_{2}$-water experiment had a 193 similar amount of trapped $\mathrm{CO}_{2}$, this would explain the rapid dissolution of $\mathrm{CO}_{2}$ observed in the 
194 early part of the experiment. This method was also abandoned due to the amount of trapped 195 phase remaining after injection.

1962.1 .3 Constant pressure: $\mathrm{CO}_{2}$ injection into an evacuated space above water-saturated porous 197 media

198 Based on the shortcomings of the previous experimental designs, the system was 199 reconfigured to inject high pressure $\mathrm{CO}_{2}$ into the top of the reactor. In these experiments, the 200 same reactor configuration described above (Fig. 2) was filled with either 500 or $180 \mu \mathrm{m}$ 201 monodispersed glass beads to test two permeability scenarios. $\mathrm{CO}_{2}$ was injected rapidly into 202 unsaturated glass-bead pack above water-saturated glass bead pack. We recognize that some 203 capillary effects and cross-flow at the interface will occur (Emami-Meybodi and Hassanzadeh, 204 2013), but this configuration minimizes the significant uncertainties associated with fluid 205 displacements during injection that result in trapped phases and capillary or viscous fingering.

206 Figure 2B schematically shows the experimental apparatus used for these experiments.

207 Experiments were conducted by filling and fully saturating the glass-bead porous media 208 with water to a known column height (based on the known porosity of the media). This was 209 achieved by first evacuating the cell with a vacuum pump and then loading from the base of the 210 column with a known mass of deionized water through a stainless-steel access tube (Fig. 2B).

211 The reactor was heated and equilibrated at the desired experimental temperature (Table 1). High 212 pressure $\mathrm{CO}_{2}$ was introduced into the top of the evacuated cell using an ISCO syringe pump 213 where it rapidly converts to the supercritical phase in the heated environment. $\mathrm{CO}_{2}$ was injected 214 rapidly until the target experimental pressure was reached (20 MPa). The water pump was set at 215 constant-pressure mode and water was added to the base of the vessel as $\mathrm{CO}_{2}$ dissolved into the 
216 water. The temperature of the reaction vessel, the pressure, and the volume of water added were

217 logged continuously at a frequency of one second.

218 Other than a short temperature anomaly created during the further compression of $\mathrm{CO}_{2}$

219 into the top of the reactor, these experiments produced excellent and repeatable results and form

220 the basis of the balance of this paper.

$221 \quad 2.1 .4$ Experimental conditions and data analysis

222 Experiments were designed to simulate a wide variety of reservoir conditions.

223 Experiments were run at $20 \mathrm{MPa}$ and 40,75 and $90^{\circ} \mathrm{C}$ using two different water column heights.

224 The relevant thermodynamic properties of $\mathrm{CO}_{2}$, water and $\mathrm{CO}_{2}$-saturated water at these

225 conditions are provided in Table 1.

Table 1. $\mathrm{CO}_{2}$ and solution properties at experimental conditions and used in PFLOTRAN simulations

\begin{tabular}{|l|l|l|l|l|l|l|l|l|}
\hline $\begin{array}{l}\mathrm{T} \\
\left({ }^{\circ} \mathrm{C}\right)\end{array}$ & $\begin{array}{l}\mathrm{CO}_{2} \mathrm{sat}^{\mathrm{a}} \\
(\mathrm{molal})\end{array}$ & $\begin{array}{l}\mu \quad \mathrm{H}_{2} \mathrm{O} \\
(\mathrm{Pa}-\mathrm{s})^{\mathrm{b}}\end{array}$ & $\begin{array}{l}\rho_{\operatorname{mix}} \\
\left(\mathrm{kg} / \mathrm{m}^{3}\right)^{\mathrm{b}}\end{array}$ & $\begin{array}{l}\rho_{\mathrm{H} 2 \mathrm{O}} \\
\left(\mathrm{kg} / \mathrm{m}^{3}\right)^{\mathrm{c}}\end{array}$ & $\Delta \rho$ & $\mathrm{D}\left(\mathrm{m}^{2} / \mathrm{s}\right)^{\mathrm{b}}$ & $\begin{array}{l}\bar{V}_{C O 2}^{a q} \\
\left(\mathrm{~cm}^{3} / \mathrm{mol}\right)^{\mathrm{b}}\end{array}$ & $\begin{array}{l}\bar{V}_{C O 2}^{0} \\
\left(\mathrm{~cm}^{3} / \mathrm{mol}\right)^{\mathrm{c}}\end{array}$ \\
\hline 40 & 1.35 & $6.51 \bullet 10^{-4}$ & 1013.6 & 1000.8 & 12.8 & $1.28 \bullet 10^{-9}$ & 33.88 & 52.40 \\
\hline 75 & 1.18 & $3.74 \bullet 10^{-4}$ & 991.73 & 983.48 & 8.25 & $2.08 \bullet 10^{-9}$ & 37.18 & 70.28 \\
\hline 90 & 1.10 & $3.10 \bullet 10^{-4}$ & 980.70 & 974.18 & 6.52 & $2.50 \bullet 10^{-9}$ & 38.43 & 82.54 \\
\hline
\end{tabular}

${ }^{\text {a }}$ Duan and Sun (2003)

$227{ }^{b}$ Density of the $\mathrm{CO}_{2}$-saturated water mixture $\left(\rho_{\text {mix }}\right)$, diffusion coefficient of $\mathrm{CO}_{2}$ in water (D), apparent

228 partial molar volume of $\mathrm{CO}_{2}$ in the aqueous phase $\left(\bar{V}_{\mathrm{CO} 2}^{a q}\right)$, obtained from PFLOTRAN calculations

229 (Lichtner and Hammond, 2012) that are consistent with the Duan et al. (2008) $\mathrm{CO}_{2}$ equation of state.

$230{ }^{c}$ Water properties from NIST thermodynamic database (Linstrom and Mallard, 2012)

The dissolution of $\mathrm{CO}_{2}$ into water results in a net decrease in volume that, in a constant-

233 volume system, results in a pressure drop. In the constant-pressure experiments, we maintain

234 pressure by addition of water to make up for the lost volume. The experimental data consist of a

235 record of the ISCO pump water flow into the reactor. This record is converted to the mass of

$236 \mathrm{scCO}_{2}$ dissolved into the water using the following approach. 
238 the reaction:

$239 \mathrm{CO}_{2(s c)} \rightarrow \mathrm{CO}_{2}(a q)$

240 This implies the following relations for the change in the number of moles of $\mathrm{CO}_{2}$ in the 241 supercritical and aqueous phases:

$242 \Delta n_{C O 2}^{s c}=-\Delta n_{C O 2}^{a q}$

$243 \mathrm{As} \mathrm{scCO}_{2}$ dissolves into the water phase in the experiment, the volume of water added to the 244 system to maintain a constant pressure, $\Delta V_{\text {isco }}$, is equal to the difference between the increase in

245 the aqueous phase volume $\left(\Delta V_{C O 2}^{a q}\right)$ and decrease in the $\operatorname{scCO}_{2}$ volume $\left(\Delta V_{C O 2}^{s C}\right)$ :

$246 \Delta V_{I S C O}=\Delta V_{C O 2}^{a q}+\Delta V_{C O 2}^{S C}$

247 and,

$248 \Delta V_{I S C O}=\Delta n_{C O 2}^{a q} \bar{V}_{C O 2}^{a q}+\Delta n_{C O 2}^{S c} \bar{V}_{C O 2}^{0}$

249 Noting equation (2), it follows that (4) can be expressed as

$250 \quad \Delta n_{C O 2}^{a q}=\frac{\Delta V_{i s c o}}{\left(\bar{V}_{C O 2}^{a q}-\bar{V}_{C O 2}^{0}\right)}$

251 where:

$252 \Delta n_{C O 2}^{a q}=$ moles of $\mathrm{CO}_{2}$ dissolved in the aqueous phase

$253 \Delta n_{C O 2}^{S C}=$ moles of $\mathrm{CO}_{2}$ in the supercritical phase

$254 \Delta V_{i s c o}=$ volume of water $\left(\mathrm{cm}^{3}\right)$ added to experiment by ISCO pump

$255 \bar{V}_{C O 2}^{a q}=$ apparent partial molar volume of $\mathrm{CO}_{2}\left(\mathrm{~cm}^{3} / \mathrm{mol}\right)$ in the aqueous phase

$256 \bar{V}_{\mathrm{CO} 2}^{0}=$ apparent partial molar volume of pure supercritical $\mathrm{CO}_{2}\left(\mathrm{~cm}^{3} / \mathrm{mol}\right)$ 
257 This approach does not consider the evaporation of water into the $\mathrm{scCO}_{2}$ phase and assumes that

258 the molar volume of the $\mathrm{scCO}_{2}$ phase is equal to the pure phase. The mole fraction of water in

$259 \mathrm{scCO}_{2}$ at $20 \mathrm{MPa}$ and $50^{\circ} \mathrm{C}$ (similar to our experiments) is $\sim 0.01$ (Sabirzyanov et al., 2002), and

260 based on the range in mass of $\mathrm{scCO}_{2}$ introduced into our experiments, this equates to a $1-4 \%$

261 error.

$262 \quad 2.2 \quad$ Modeling Methods

263 We used PFLOTRAN, a multiphase, multicomponent reactive flow and transport code

264 that works on laptops to supercomputers. The massively parallel framework is based on Message

265 Passing Interface (MPI) and uses the Parallel Extensible Toolkit for Scientific Computing

266 (PETSc; Lichtner and Hammond 2012). The code is licensed under an open source GNU Lesser

267 General Public License. We used the code to model the experiments and to allow extrapolation

268 of the experimental results to $\mathrm{CO}_{2}$ sequestration reservoir conditions.

\section{$269 \quad 2.2 .1 \quad$ Simulation Setup}

270 The simulations were conducted in a rectangular prism with depth equal to the depth of

271 the water in the experiments and a square cross-section equal in area to the circular area of the

272 experimental cylinder. This results in a rectangular prism with base of $0.05557 \mathrm{~m}$ and height

273 between 0.10 and $0.25 \mathrm{~m}$. The simulated domain contained a single aqueous phase with an

274 imposed boundary condition at the top of the prism having a constant concentration slightly less

275 than saturation (to ensure a single phase) of $\mathrm{scCO}_{2}$ at the temperature and pressure of the

276 simulation. Boundary conditions at the sides and bottom were zero gradient. During the

277 simulation, $\mathrm{CO}_{2}$ diffuses from the top boundary into the model domain. After a period of time

278 (the onset time, $t_{\text {on }}$ ), fingers form and advective mixing begins. In our initial approach, we 
279 allowed numerical noise to seed the formation of advective fingering in a model domain 280 containing pure water.

281 In order to assess numerical convergence, we examined the effect of grid resolution in 282 terms of the following criteria: 1) onset time (measured by a macroscopic departure of the 283 dissolution rate from square-root of time behavior); 2) rate of $\mathrm{CO}_{2}$ dissolution during steady-state 284 advection; 3) time to achieve 33,50 , and $66 \%$ saturation measured from the onset time; and 4) 285 finger pattern development. We found that the rate of dissolution and the time to saturation 286 converged, but that the onset time and the finger patterns were unpredictable or chaotic. The 287 fingering pattern was highly non-linear, such that infinitesimal changes in initial conditions 288 produced markedly different finger patterns and a variable onset time to advection. We also 289 observed that increasing refinement in the z-direction resulted in a steady decrease in the onset 290 time for convection, although rates and the time to saturation were steady. In order to achieve 291 grid convergence and to make our simulations across a range of conditions (Rayleigh numbers, 292 see section 3.1) more comparable, we seeded the simulations with an initial perturbation of the 293 concentration (Fig. 3). We placed 13 perturbations of either 0.004598 or $0.002294 \mathrm{~m}$ thickness at 294 the top surface of the system with a uniform concentration of 0.0132 molal (about $1 \%$ of 295 saturation). The remainder of the system was initialized with zero concentration of $\mathrm{CO}_{2}$.

296 The perturbations removed the dependence of onset time on the z-refinement and created 297 reproducible finger patterns that were not sensitive to infinitesimal changes in conditions. We 298 found that a $30 \times 30 \times 200$ grid was converged for both the high and low permeability experiment, 299 resulting in cells that were $0.00185 \times 0.00185 \mathrm{~m}$ in the $\mathrm{x}-\mathrm{y}$ plane and $0.001-0.002 \mathrm{~m}$ along the $\mathrm{z}$ 300 axis. 
In the calculations presented below, we use the perturbed concentration condition. We

302 recognize that the true experimental conditions were not characterized by this particular

303 perturbation pattern. However, the experiments could not be created with a mathematically

304 perfect separation between $\mathrm{CO}_{2}$ and water, and thus had an unknown and variable perturbation as

305 reflected by the absence of any obvious onset time to advection (see section 3.1). The advantage

306 of using perturbations in the simulations is that we can more easily analyze the effect of

307 changing conditions (Rayleigh number) on the rate of $\mathrm{CO}_{2}$ dissolution in order to predict

308 behavior of sequestration-scale systems. In any case, this perturbation sensitivity is likely to be

309 important only at the scale of our experiments. At large scale, the perturbations are a small

310 fraction of the total mixing process.

\section{3. Results}

\section{$312 \quad 3.1 \quad$ Scalability of experimental results}

313 One of the goals of this paper is to provide results that are scalable to other analog 314 experiments and to geologic reservoir conditions. To do this we follow the approach of previous 315 studies representing key parameters with dimensionless numbers (e.g, Prasad and Simmons, 316 2003; Neufeld et al., 2010; Backhaus et al., 2011). First, we use the Rayleigh number to assess

317 the convective driving force relative to diffusion as defined by (e.g., Riaz et al., 2006; Backhaus 318 et al., 2011). This allows our different cell configurations to be compared to other experiments, 319 models, and geological systems with similar Rayleigh numbers.

$320 R a=\frac{k g H \Delta \rho}{\phi D \mu}$

321 where:

$322 k=$ permeability $\left(\mathrm{m}^{2}\right)$

$323 g=$ gravitational constant $\left(\mathrm{m} / \mathrm{s}^{2}\right)$ 
$324 H=$ height of water column (m)

$325 \Delta \rho=$ difference in density between $\mathrm{CO}_{2}$ saturated water and water $\left(\mathrm{kg} / \mathrm{m}^{3}\right)$

$326 \phi=$ porosity

$327 \quad D=$ diffusion coefficient $\left(\mathrm{m}^{2} / \mathrm{s}\right)$

$328 \mu=$ dynamic viscosity of water $(\mathrm{Pa} \cdot \mathrm{s})$

329 Secondly, we define $t^{*}$ as the experimental time $(t)$ normalized to the convective time $\left(t_{\mathrm{C}}\right)$.

330 The convective time is defined as the time required for a finger of $\mathrm{CO}_{2}$-saturated water to travel

331 from the $\mathrm{CO}_{2}$-water interface to the base of the column (or aquifer) (Backhaus et al., 2011).

$332 t^{*}=\frac{t}{t_{C}}$

$333 t_{C}=\frac{\phi \mu H}{k g \Delta \rho}=\frac{H}{v_{c}}$

334 where: $v_{c}=$ is the Darcy pore velocity for a finger of $\mathrm{CO}_{2}$-saturated water.

335 Finally, we calculate a dimensionless $\mathrm{CO}_{2}$ flux relating the convective mass transfer to

336 diffusive mass transfer. Here we define the Nusselt number $(\mathrm{Nu}$; also known as the Sherwood

337 number) as:

$338 \quad N u=\frac{\dot{M}}{\dot{M}_{D}}$

339 where:

$340 \dot{M}=$ measured mass transfer (dissolution) rate $(\mathrm{mol} / \mathrm{s})$

$341 \dot{M}_{D}=$ diffusive mass transfer (dissolution) rate $(\mathrm{mol} / \mathrm{s})$

342 Diffusive mass transfer is calculated for a 1-D semi-infinite medium with a constant surface

343 concentration $\left(\mathrm{C}_{0}\right)$ using (Crank, 1956):

$344 \quad N(t)=2 A C_{0} \sqrt{\frac{D_{e} t}{\pi}}$ 
$345 \quad \frac{d N}{d t}=A C_{0} \sqrt{\frac{D_{e}}{\pi t}}$

346 where:

$347 \quad A=$ cross sectional area $\left(\mathrm{m}^{2}\right)$

$348 C_{0}=$ saturated $\mathrm{CO}_{2}$ concentration at $\mathrm{P}, \mathrm{T}\left(\mathrm{mol} / \mathrm{cm}^{3}\right)$

349 and,

$350 D_{e}=0.66 D \phi=$ the effective diffusion coefficient (Penman, 1940; Weissberg, 1963).

351 Our experiments show how the rate of $\mathrm{CO}_{2}$ dissolution (i.e., $\mathrm{mol} / \mathrm{s}$ ) changes with time,

352 and the Nusselt number (or Sherwood number) allows us to evaluate how the rate compares to

353 dissolution by diffusive processes only where $\mathrm{Nu}=1$. Additionally, how the Nusselt number

354 changes during the experiment is compared to reaction progress towards system saturation,

355 providing insight into how the phenomenon of convective mixing evolves in a reservoir.

$356 \quad 3.2 \quad$ Experiments

357 A total of eight experiments were conducted spanning Rayleigh numbers from 2093 to

358 16256, calculated using equation (6) with the height of the water column in the experiment and

359 other properties given in Table 2. Different combinations of temperature, water column height

360 and permeability (via bead size) were used to create this range in Rayleigh numbers. Figure 4a

361 shows the raw data collected for one experiment in terms of water added to the reactor by the

362 ISCO pump. Figure $4 \mathrm{~b}$ illustrates the conversion from the water volume record to the moles of

$363 \mathrm{CO}_{2}$ dissolved using equation (5). To calculate the rate of dissolution, the record of moles

364 dissolved is differentiated with respect to time. Because of experimental noise (e.g., pump motor

365 oscillations) in the volume record, a smoothing function is applied prior to differentiation.

366 To test repeatability of experiments, duplicate runs for the $\mathrm{Ra} \sim 16000$ and $\mathrm{Ra} \sim 2000$

367 experiments were conducted. Figure 5 shows the $\mathrm{Ra}=16133$ and 16256 experiments (Table 2) 
368 in terms of moles dissolved and rates of dissolution. Note that the experiments closely track one

369 another in rate. There is a slight difference in the absolute moles dissolved over time, resulting

370 in the two experiments reaching saturation at slightly different times. This is due in part to the

371 small differences in the starting mass of water (difference of $\sim 2 \mathrm{~g}$ ), and due to differences in the

372 amount of $\mathrm{CO}_{2}$ dissolved during the earliest times of the experiment (see additional discussion

373 later).

Table 2. Experimental parameters for $\mathrm{CO}_{2}$ dissolution experiments. Ra and $t_{\mathrm{C}}$ defined above

\begin{tabular}{|l|c|c|l|l|l|l|l|}
\hline $\mathrm{T}\left({ }^{\circ} \mathrm{C}\right)$ & $\begin{array}{c}\mathrm{H}_{2} \mathrm{O} \\
(\mathrm{g})\end{array}$ & $\begin{array}{c}\mathrm{H}_{2} \mathrm{O} \\
(\mathrm{ml})\end{array}$ & $\begin{array}{c}\mathrm{H}_{2} \mathrm{O} \text { height } \\
(\mathrm{cm})\end{array}$ & $\begin{array}{c}\text { bead } \\
\text { diameter } \\
(\mu \mathrm{m})\end{array}$ & $\mathrm{k}\left(\mathrm{m}^{2}\right)^{\mathrm{a}}$ & $\mathrm{Ra}$ & $t_{\mathrm{c}}(\mathrm{s})$ \\
\hline 40 & 261.99 & 261.77 & 23.10 & 500 & $1.71 \cdot 10^{-10}$ & 16256 & 2570 \\
\hline 40 & 260.00 & 259.79 & 22.92 & 500 & $1.71 \cdot 10^{-10}$ & 16133 & 2556 \\
\hline 75 & 195.99 & 199.28 & 17.58 & 500 & $1.71 \cdot 10^{-10}$ & 8540 & 1728 \\
\hline 40 & 200.34 & 200.18 & 17.66 & 500 & $1.71 \cdot 10^{-10}$ & 12431 & 1966 \\
\hline 90 & 150.06 & 154.03 & 13.59 & 500 & $1.71 \cdot 10^{-10}$ & 5236 & 1404 \\
\hline 75 & 160.00 & 162.69 & 14.35 & 500 & $1.71 \cdot 10^{-10}$ & 6972 & 1422 \\
\hline 40 & 260.46 & 260.25 & 22.96 & 180 & $2.22 \cdot 10^{-11}$ & 2095 & 19728 \\
\hline 40 & 260.20 & 260.00 & 22.94 & 180 & $2.22 \cdot 10^{-11}$ & 2093 & 19710 \\
\hline
\end{tabular}

${ }^{a}$ Calculated using Kozeny-Carmen correlation (Carman, 1937): $\mathrm{k}\left(\mathrm{m}^{2}\right)=\varnothing^{3} \mathrm{~d}^{2}(1-\varnothing)^{2} / 180$, where $\varnothing$ is the effective porosity and $\mathrm{d}=$ grain diameter $(\mathrm{m})$.

374 Four of the experiments spanning the range of Rayleigh numbers investigated are

375 highlighted in figure 6 to illustrate the observed rates of $\mathrm{CO}_{2}$ dissolution and the number of

376 moles dissolved. This is plotted with respect to convective time to aid graphical comparison

377 because the low Ra experiments have a much lower permeability and required a much longer

378 experimental time. Each experiment reached a different total moles- $\mathrm{CO}_{2}$ dissolved because each

379 experiment contained a different starting mass of water and the solubility of $\mathrm{CO}_{2}$ differs for the

38040,75 and $90^{\circ} \mathrm{C}$ experiments (Table 2). Analysis of the fluids after the experiments were

381 concluded indicate they all reached saturation within $+/-2 \%$ of the predicted values in Table 1 .

382 The rate curve shows several different periods during the experiment: early rates are high and 
383 rapidly decrease $\left(t^{*}=\sim 1\right)$; this is followed by a period of quasi-steady state rates $\left(t^{*}=\sim 1-5\right)$; at 384 the end of this period rates drop rapidly until approximately $t^{*}=\sim 10$ and then decrease 385 asymptotically to very low rates on the order of $\sim 10^{-8}$ to $10^{-7} \mathrm{~mol} / \mathrm{s}$ for the duration of the 386 experiments. These lowest rates are near the measured experimental leak rate (pumps, fittings 387 and reactor). Note that the $\mathrm{Ra}=8450-16133$ had quasi-steady state rates ranging from $\sim 1.2-$ $3881.4 \cdot 10^{-5} \mathrm{~mol} / \mathrm{s}$. The $\mathrm{Ra}=2093$ experiment had $\sim 5 \mathrm{x}$ slower rates during this period in the range of $3892.5-3 \times 10^{-6} \mathrm{~mol} / \mathrm{s}$. The low Ra experiment had a permeability $\sim 8 \mathrm{x}$ lower than the higher $\mathrm{Ra}$ 390 experiments with 500 micron beads.

$391 \quad 3.3 \quad$ Modeling

392 3.3.1 Empirical analysis

393 As a first step to interpreting $\mathrm{CO}_{2}$ dissolution mass and $\mathrm{CO}_{2}$ dissolution rate (e.g., Fig. 4 $394 \& 6$ ), we further analyzed the $\mathrm{Ra}=16133$ experiment with empirical fits to segments of the 395 results. Three distinct regimes are revealed from a log-log plot of the $\mathrm{CO}_{2}$ dissolution rate and 396 the total moles of $\mathrm{CO}_{2}$ dissolved (Fig. 7). In this plot, rate $=\mathrm{dN} / \mathrm{dt}$, where $\mathrm{N}$ denotes the total 397 number of moles of $\mathrm{CO}_{2}$. The first regime is fit with $\mathrm{N} \sim \mathrm{t}^{0.5}$ and $\mathrm{dN} / \mathrm{dt} \sim \mathrm{t}^{-0.5}$. This regime 398 extends over the interval $100<\mathrm{t}<2000 \mathrm{~s}$. The second regime is marked by a constant rate of 399 dissolution $(\mathrm{N} \sim \mathrm{at}, \mathrm{dN} / \mathrm{dt} \sim \mathrm{a})$, which extends over the time interval $5000<\mathrm{t}<15000 \mathrm{~s}$. The 400 third regime extending over the interval $15000<\mathrm{t}<50000 \mathrm{~s}$ can be fit with a 1.75 power law: $401 \mathrm{dN} / \mathrm{dt} \sim \mathrm{t}^{-1.75}$. To obtain a fit to $\mathrm{N}(\mathrm{t})$, this expression can be integrated to give the relation: $\mathrm{N}(\mathrm{t})=$ $402 \mathrm{a}-\mathrm{b} \mathrm{t}^{-0.75}$.

403 The first regime that follows a $\mathrm{t}^{-0.5}$ power law is consistent with diffusion, and the 404 constant rate segment is interpreted as the onset of convection and steady flow of convective 
405 fingers in the experiments. The third regime likely is due to descending fingers encountering the

406 bottom of the column. These regimes are further discussed in section 4.1.

\subsubsection{PFLOTRAN Simulations}

We conducted 18 numerical simulations using PFLOTRAN at a range of conditions spanning the experiments and designed to allow extrapolation of experimental results to

410 sequestration-scale conditions. In this section, we first validate the numerical simulations by

411 comparison with experimental data and visualize the mixing behavior in the $\mathrm{scCO}_{2}$-brine system,

412 in particular finger patterns and rates of descent. We then use the numerical model at a range of

413 other conditions to develop parametric relationships among key dimensionless variables

414 (Rayleigh number and convective time) to allow extrapolation of the experimental results to the

415 field-scale. Table 3 shows the parameters and results from 4 representative simulations, and

416 Table S1 in the supplemental information provides details for all 18 simulations.

Table 3. List of parameters and results from numerical simulations 1, 2, 13, and 15 of densityinduced mixing.

\begin{tabular}{|c|c|c|c|c|}
\hline Simulation & 1 & 2 & 13 & 15 \\
\hline $\mathbf{T}\left({ }^{\circ} \mathbf{C}\right)$ & 40 & 40 & 75 & 90 \\
\hline Bead dia. (m) & $5.0 \cdot 10^{-4}$ & $1.8 \cdot 10^{-4}$ & $5.0 \cdot 10^{-4}$ & $5.0 \cdot 10^{-4}$ \\
\hline$\square$ & 0.367 & 0.367 & 0.367 & 0.367 \\
\hline $\mathbf{k}\left(\mathrm{m}^{2}\right)$ & $1.71 \cdot 10^{-10}$ & $2.22 \cdot 10^{-11}$ & $1.71 \cdot 10^{-10}$ & $1.71 \cdot 10^{-10}$ \\
\hline Depth (m) & 0.229 & 0.229 & 0.176 & 0.136 \\
\hline $\operatorname{Area}\left(m^{2}\right)$ & $3.09 \cdot 10^{-3}$ & $3.09 \cdot 10^{-3}$ & $3.09 \cdot 10^{-3}$ & $3.09 \cdot 10^{-3}$ \\
\hline Ra & 16100 & 2090 & 8520 & 5230 \\
\hline$t_{\mathrm{on}}(\mathrm{s})$ & 49.5 & 2940 & 81.4 & 108 \\
\hline$t_{C}(\mathbf{s})$ & 2560 & 19700 & 1740 & 1410 \\
\hline Rate-obs (mol/s) & $1.20 \cdot 10^{-5}$ & $1.80 \cdot 10^{-6}$ & $1.02 \cdot 10^{-5}$ & $9.51 \cdot 10^{-6}$ \\
\hline Onset-obs (s) & 198 & 4160 & 194 & 194 \\
\hline Sat. at onset (mol fraction) & $1.20 \cdot 10^{-3}$ & $9.60 \cdot 10^{-3}$ & $1.00 \cdot 10^{-3}$ & $1.00 \cdot 10^{-3}$ \\
\hline t sat. $0.33(s)$ & $7.73 \cdot 10^{3}$ & $6.80 \cdot 10^{4}$ & $5.44 \mathrm{E} \bullet 10^{3}$ & $4.14 \cdot 10^{3}$ \\
\hline t sat. $0.5(s)$ & $1.41 \cdot 10^{4}$ & $1.12 \cdot 10^{5}$ & $1.04 \cdot 10^{4}$ & $8.00 \cdot 10^{3}$ \\
\hline t sat $0.66(s)$ & $2.00 \cdot 10^{3}$ & $1.65 \cdot 10^{5}$ & $1.51 \cdot 10^{4}$ & $1.18 \cdot 10^{4}$ \\
\hline t at bottom (s) & $7.02 \cdot 10^{3}$ & $8.57 \cdot 10^{4}$ & - & - \\
\hline \# fingers & 11.5 & 2.25 & - & - \\
\hline
\end{tabular}

All runs conducted on rectangular prisms at a pressure of $20 \mathrm{MPa}$. The Ra, $t_{\mathrm{on}}$, and $t_{\mathrm{C}}$ and other symbols are defined in the text; Rate-obs. is the observed rate at a saturation of 0.33 ; $\mathrm{t}$ sat $0.33,0.5$, and 0.66 refer to the observed time at a saturation of $0.33,0.5$, and 0.66 , respectively; $t$ at bottom refers to the time for the fingers to reach the bottom of 
the system.

We show example results for simulations 1 and 2 in figure 8 . These simulations differ in

419 Rayleigh number by about a factor of 10 due to the use of different bead sizes with different

420 permeability. This resulted in the time for the $\mathrm{CO}_{2}$-rich fingers to reach the bottom of the model

421 to differ by about a factor of 10 . The number of fingers differed markedly from about 11 for the

422 high-Rayleigh number experiment to about 2 for the low-Rayleigh number experiment.

\section{$423 \quad 3.2 .1 \quad$ Simulation Results}

$424 \quad$ Figure 9 shows the simulation results for four PFLOTRAN models designed to match the 425 Ra 16133 (simulation \#1 in Table 3), 8540 (simulation \#13), 5263 (simulation \#15), and 2093 426 (simulation \#2) experiments shown in figure 6. These are plotted in terms of molal concentration 427 of dissolved $\mathrm{CO}_{2}$ in real time; the associated experimental results for these four examples are 428 included for comparison. Figure 9B presents results for the first 100,000 seconds of the high 429 permeability cases.

430 The simulations do not reproduce the experimental data exactly, but show general 431 agreement in the slope (rate of dissolution). Much of the difference between the simulations and 432 experiments can be explained by the difference in onset behavior, as discussed below, which 433 suggests that the model is adequately reproducing the behavior of the experiments.

\section{$434 \quad 4.0 \quad$ Discussion}

435 4.1 Dimensional Analysis

436 Representing the experimental results in terms of dimensionless numbers allows for 437 comparison to analog fluid experiments, modeling efforts, and for scaling to reservoir conditions. 438 Figure 10 presents the experimental results in terms of Nusselt number $(\mathrm{Nu})$, fraction saturated 
$439\left(\mathrm{~F}=1\right.$ for $100 \% \mathrm{CO}_{2}$ saturated water) and normalized convective time $\left(t^{*}\right)$. Four segments of the $440 \mathrm{Nu}$ vs. $t^{*}$ curves are identified (A-D, figure 10).

441 Based on observations 1) made during 2D Hele-Shaw PPG-water experiments (Backhaus 442 et al., 2011) and 2) from our empirical analysis of experiment $\mathrm{Ra}=16133$ in figure 7, these 443 segments are interpreted as follows: During segment (A) $\mathrm{scCO}_{2}$ rapidly diffuses into the water 444 building up a dense layer that begins to convect once it becomes gravitationally unstable. 445 Theoretically, diffusion should dominate early on with rates that rapidly decrease as the diffusive 446 layer builds and diffusion gradients decrease (e.g, Ennis-King et al., 2005; Ennis-King and 447 Paterson, 2007; Pau et al., 2010). Once this layer becomes unstable, rates should rapidly increase 448 as convection starts. Our results generally show this, but in contrast to these computational 449 studies, this early onset time in our experiments is shorter and characterized by higher-than 450 predicted diffusion rates. Segment A transitions to B and the onset of steady flow by convection. 451 Segment (B) represents a quasi-stable pattern of descending fingers of $\mathrm{CO}_{2}$ saturated water from 452 the interface between the fluids. $\mathrm{Nu}$ increases steadily during this time to a maximum at $\mathrm{C}$ on 453 Fig. 10 (e.g., Ra 16133 increases to a $\mathrm{Nu}$ maximum $=35$ ). Recall that $\mathrm{Nu}$ is the ratio of the 454 measured $\mathrm{CO}_{2}$ flux to the flux predicted by diffusion alone (eq. 9), and the increase in $\mathrm{Nu}$ during 455 this time is consistent with this phenomenon (Hassanzadeh et al., 2007). After Nu maximums at $456 \mathrm{C}$, the convective rates slow relatively rapidly and asymptotically decline to low $\mathrm{Nu}$ (segment 457 D). We interpret this to represent the period after the fingers "see" and reach the bottom of the 458 column, and the system slowly relaxes to mass transfer dominated by diffusion $(\mathrm{Nu}=1$ after 20 459 convective times, not shown).

460 In contrast to figure 6, the mass consumed is represented as the fraction saturated (F) in 461 figure 10 (right axis). Whereas each experiment follows a unique dissolution path in figure 6, 
462 they follow very similar paths in terms of $\mathrm{F}$ in figure 10. With respect to convective time, each 463 experiment should theoretically follow the exact same path to $100 \%$ saturation $(\mathrm{F}=1)$. However, 464 these pathways show some variability. The data are plotted out to 20 convective times, and the 465 experiments that appear not to have reached saturation $(\mathrm{F}=1)$ actually approach or slightly 466 exceed saturation (within 2\%), based on analysis of the fluids.

467 The early high rates and onset of convection, and the variability in the saturation data are 468 in part due to experimental limitations. It was not possible to create an interface between the 469 fluids that was a smooth plane. First, injection likely results in some unknown amount of 470 topography at the interface. Secondly, a partially water-saturated capillary fringe exists at the top 471 of the water column in the glass bead pack prior to $\mathrm{CO}_{2}$ injection into the experiment. And 472 thirdly, recent numerical studies support the presence of a 2-phase capillary transition zone 473 between the $\mathrm{scCO}_{2}$ and water (Emami-Meybodi and Hassanzadeh, 2013, 2015; Emami-Meybodi 474 et al., 2015). These studies suggest that the development of a capillary transition zone, its upward 475 migration during $\mathrm{CO}_{2}$ dissolution, and some cross-flow in this interface lead to higher early rates 476 of dissolution and a shorter onset time to convection. In our experiments, all of these factors 477 increase the surface area between the fluids to an unknown extent, and this phenomenon will be 478 unique from experiment to experiment. Thus, the result of this is that the experiments reach a 479 variable $10-20 \%$ saturation prior to the onset of convection.

480 Note the systematic reduction in $\mathrm{Nu}$ with decreasing Rayleigh number for the pseudo481 steady state period between 1 and 5 convective times in figure 10. The Nu numbers range from $4827-35$ during this period, and this means that due to convection the rate of mass transfer is $7-35$ 483 times faster than predicted by diffusion alone. Also note that by the time convection has slowed 
484 and presumably fingers of $\mathrm{CO}_{2}$-saturated water reach the base of the reaction cell at $\sim 10$

485 convective times, all experiments are between 75 and $85 \%$ saturated.

4864.2 Comparison of experiments to PFLOTRAN simulations

487 To further interpret the experiments and to serve as a model validation exercise, the 488 experiments were simulated using PFLOTRAN. Figure 9A and B show comparisons between 489 the $\mathrm{Ra}=16133,8540,5236$ and 2093 experiments, which span the conditions investigated and 490 highlight the impact of different permeabilities. Figure 11 zooms in on the early part of the 491 experiments and models for the low (k2) and high (k1) permeability $40^{\circ} \mathrm{C}$ cases.

492 Figures 9 and 11 show some similarities and some key differences between the model 493 and experiments. First the $500-\mu \mathrm{m}$ bead (k1) experiments and model show very similar curve 494 shapes in terms of slope, and asymptotic approach to saturation (Figure 9A; 1.1 to 1.35 molal). 495 The $180-\mu \mathrm{m}$ bead $(\mathrm{k} 2)$ experiment shows greater difference, although it eventually converges on 496 the same saturation condition of 1.35 molal (the model takes significantly longer to converge on 497 saturation and is not depicted on Fig. 9). Note that both model runs show an initial "onset" time 498 (B, Fig. 11), characterized by low rates. This represents early build-up of the diffusive layer 499 prior to the onset of gravitational instability and convection. In contrast, the early parts of the 500 experiments show much higher rates of dissolution of $\mathrm{CO}_{2}$ before transitioning to steady-state 501 rates (A, Fig. 11). Once convection starts in the simulations, the modeled rates dramatically 502 increase and are near steady state with good agreement between experiment and simulation (note 503 similar slopes between experiment and simulations in Figures 9 and 11). Once the fingers 504 approach the bottom of the simulated reaction vessel, rates slow and asymptotically approach 505 saturation with simulations capturing this behavior quite well (Figure 9). 
This difference in behavior between the early time in the experiment and model is

507 attributed to an imperfect interface between $\mathrm{CO}_{2}$ and water in the experiments and the sharp

508 interface in the model, as previously discussed. Thus, the experiments have much a much shorter

509 onset time with high rates of diffusion, reach gravitational instability and convection faster, and

510 ultimately reach saturation faster. Note that the low permeability experiment $(\mathrm{k} 2)$ reaches a

511 higher level of initial saturation than the higher permeability experiment (k1) (nearly $0.2 \mathrm{~m}-\mathrm{CO}_{2}$

512 compared to $<0.1 \mathrm{~m}-\mathrm{CO}_{2}$ ) (Fig. 11), and this is likely due to a more pronounced capillary fringe

513 developed in the low permeability case because of the smaller beads (higher capillary forces).

514 To account for these differences and better compare the experimental and model results

515 after the onset of steady flow, the model results were adjusted in time (onset time removed) and

516 concentration (an early $\mathrm{CO}_{2}$ addition) (Fig. 12). Although the match between the model and the

517 experiments is greatly improved for the high permeability case $(\mathrm{k} 1)$, some key differences are

518 seen between the lower permeability $(\mathrm{k} 2)$ results. The model runs show a near steady-state rate

519 of dissolution followed by an asymptotic decline in rates to saturation, but the experiments

520 (especially the lower permeability case) show a less persistent steady-state period. Rates are

521 initially higher than the model rates, followed by a decline to below model rates prior to

522 asymptotically reaching saturation. Ideally, the steady-state period represents a period of free

523 convection of dense $\mathrm{CO}_{2}$-saturated fingers. The asymptotic rollover is indicative of the fingers

524 reaching the bottom of the cell with a resultant reduction of mixing rates until saturation is

525 reached. The higher early dissolution rates in the experiments are likely due to a superposition

526 of the high early rates driven by diffusion along the interface as previously discussed and free

527 convection rates. The subsequent slowing of experimental rates to below those seen in the model

528 could be due to the build-up of a thicker diffusive layer at the $\mathrm{CO}_{2}$-water interface or that the 
529 experiment simply reached a higher saturation state earlier, reducing the density gradient driving

530 convection.

5314.3 Scaling to Reservoir Conditions

532 The goals of benchmarking PFLOTRAN with the $\mathrm{CO}_{2}$ dissolution experiments include 533 developing a tool for scaling up to reservoir conditions, and to calculate reservoir specific

534 dissolution times for emplaced $\mathrm{CO}_{2}$ plumes. Convective time ( $t_{C}$, equation 8 ) is chosen as an 535 easy-to-compute, reservoir-specific term to estimate the length of time required to transfer 536 supercritical $\mathrm{CO}_{2}$ to brine by dissolution and gravitational mixing. Figure 13 displays the 537 convective time against the amount of time required to reach various levels of saturation $(33,50$ 538 and 66\%) for the PFLOTRAN simulations conducted and the associated experiments. Note that 539 the amount of time required is well fit by a power-law function of the convective time over the 540 range of reservoir conditions simulated. As seen in the previous comparisons of the experiments 541 to the simulations, the experiments reach the various levels of saturation before the simulations. 542 Also, the relative fit between the experiments and simulations in terms of the absolute time and 543 the slope of the saturation time - convective time power relationship improves with increasing 544 levels of saturation.

545 Specifically, the match between experiments and models is quite poor at $33 \%$ of 546 saturation. This is best explained by the previous observations that dissolution and mixing 547 behavior during the early part of the experiments is variable and accelerated compared to the 548 simulations due to the short onset time and early rapid dissolution driven by diffusion due to an 549 imperfect interface between the fluids (e.g., capillary fringe, cross-flow, topography).

\section{$550 \quad 5.0 \quad$ Conclusions}


One of the primary concerns with geological carbon sequestration is that the buoyant $\mathrm{CO}_{2}$

552 plume will persist for centuries increasing the risk of migration from the target storage reservoir

553 to shallower environments. Convective mixing of $\mathrm{CO}_{2}$-saturated brine has the potential to

554 greatly reduce the lifetime of the buoyant plume alleviating some of the concern and allowing for

555 greater masses of $\mathrm{CO}_{2}$ injection. Since field-scale experiments addressing this phenomenon are

556 not practical, this process has been addressed through computational efforts and laboratory

557 experiments using analog fluids. The at-conditions $\mathrm{CO}_{2}$-water experiments presented here

558 bridge the gap between computational and analog experimental studies.

559 Based on these experiments, the observed mass transfer rates due to convective mixing

560 ranged from $0.5 \times 10^{-5}$ to $1.5 \times 10^{-5} \mathrm{~mol} / \mathrm{s}$ (or a flux of $1.6 \times 10^{-2}$ to $4.8 \times 10^{-3} \mathrm{~mol} / \mathrm{s} / \mathrm{m}^{2}$ ). When

561 represented as dimensionless Nusselt numbers, the experiments show a systematic pattern of 7 -

56235 X enhancement in rates over diffusion for Rayleigh numbers from 2093 to 16133 . In terms of

563 normalized convective time $\left(t^{*}\right)$, which can be converted to real time for specific reservoir

564 conditions (equations 7 and 8), the experiments all reached 50\% saturation within 5 convective

565 times, and $75-85 \%$ saturation within 10 convective times.

566 In comparison to model simulations, the experiments show a much shorter onset period

567 of convection with high diffusion rates. This is attributed to a heterogeneous interface with

568 significant topography (heterogeneity) between fluids in the experiments as compared to the

569 idealized planar interface in the model simulations. In order to more closely reproduce the

570 experiments, the model would need to incorporate some type of topography to the initial

571 boundary between $\mathrm{CO}_{2}$ and water and to account for capillary processes (e.g., Emami-Meybodi

572 and Hassanzadeh, 2013). However, the experiments with a heterogeneous interface and capillary

573 fringe may better represent the reality of an actual $\mathrm{CO}_{2}$ storage reservoir. In the natural 
574 environment, the $\mathrm{CO}_{2}$ plume will spread against the caprock-reservoir boundary, and it is likely

575 that the resulting $\mathrm{CO}_{2}$-brine interface would have topography and a capillary transition zone,

576 which would result in a more rapid onset of instability in the dissolved $\mathrm{CO}_{2}$ plume. In addition to

577 heterogeneity related to the $\mathrm{CO}_{2}$-water interface, the experiments and modeling only considered

578 a homogeneous porous medium. It is expected that heterogeneity in real reservoirs will result in a

579 similar reduction in onset time of convection and a net increase in early rates of mass transfer,

580 but this was not explored in this study.

$581 \quad 6.0 \quad$ Acknowledgements

582 Funding for this study was generously provided by the Los Alamos National Laboratory LDRD

583 program (\#20100025DR). We thank H. Hassanzadeh and 2 anonymous reviewers for

584 constructive reviews that greatly improved the manuscript.

585

586 FIGURE CAPTIONS

587 Figure 1. Schematic of constant volume experiment configuration. The vessel was oriented

588 horizontally and injection of $\mathrm{CO}_{2}$ occurred at mid-height of the porous media.

589

590 Figure 1. Schematic of constant pressure experiments. A. Water displacement of $\mathrm{scCO}_{2}$ -

591 saturated porous media. Water is injected into the base until desired volume and resulting

592 column height of water is reached. B. High pressure $\mathrm{CO}_{2}$ injection into unsaturated porous

593 media above water-saturated porous media.

594

595 Figure 3. Perspective view of the initial conditions of the simulation domain showing the

596 concentration perturbation imposed on the top boundary of the model. 
598 Figure 4. $40^{\circ} \mathrm{C}, 20 \mathrm{MPa}, \mathrm{Ra}=16133 \mathrm{~A}$ : Experimental record of the volume of water added to

599 the reactor as $\mathrm{CO}_{2}$ dissolves. B: Experiment record corresponding to (A) showing the amount of $600 \mathrm{CO}_{2}$ (moles) dissolved over time and the rate of dissolution. The number of moles is derived 601 from the volume of water record using equation (5). The rate of dissolution is determined by 602 differentiating the smoothed mass versus time record. Note the very rapid initial dissolution rate 603 followed by a relatively steady state plateau out to $\sim 20000$ seconds, followed by a further decline 604 in rates.

Figure 5. Duplicate experiments: $40^{\circ} \mathrm{C}, 20 \mathrm{MPa}$, column height $\sim 23 \mathrm{~cm}$ (see Table 2). The 607 smooth curves are moles dissolved, and the records with more noise are the rate of dissolution.

608 Red curve $=$ Ra 16256; black curve $=$ Ra 16133.

610 Figure 6. Results $\left(\mathrm{CO}_{2}\right.$ dissolution rate in $\mathrm{mol} / \mathrm{s}$ and moles of $\mathrm{CO}_{2}$ dissolved) of experiments at 6114 different Rayleigh numbers. The results are presented versus $t^{*}$ to allow for comparison of 612 rates between the $\mathrm{Ra}=16133-8450$ experiments with the $\mathrm{Ra}=2093$ experiment, which had a 613 lower permeability and much longer run time.

615 Figure 7. Empirical curve fits of the $40^{\circ} \mathrm{C}, 200 \mathrm{bar}, \mathrm{Ra}=16133$ experiment, presented in linear 616 (left) and log-log (right) space. $\mathrm{N}(\mathrm{t})=$ moles of $\mathrm{CO}_{2}$ dissolved over time, and $\mathrm{dN} / \mathrm{dt}=$ rate of $\mathrm{CO}_{2}$ 617 dissolution. See text for explanation of the empirical curve-fits.

619 Figure 8. A comparison of the finger structure of simulations 1 (left) and 2 (right) of Table 3. 620 The images were captured at differing times corresponding to when the fingers reached the 621 bottom of the system ("t at bottom" of Table 3). The fingers are contoured in terms of mole 
622 fraction of $\mathrm{CO}_{2}$ in the aqueous phase. Two views of each experiment are shown (view up

623 through bottom and a perspective view). The number of fingers was calculated from the bottom

624 view. In these simulations, $\mathrm{CO}_{2}$ saturation is 0.0243 mole-fraction.

Figure 9. (A) Comparison of PFLOTRAN simulations of experiments (dashed curves) to 627 experimental data (solid curves) for four cases with 40,75 and $90^{\circ} \mathrm{C}+500 \mu \mathrm{m}$ beads $(\mathrm{k} 1$ ), and 628 the $40^{\circ} \mathrm{C}+180 \mu \mathrm{m}$ beads $(\mathrm{k} 2)$. The Ra for each experiment and simulation is shown in 629 parentheses. The $75^{\circ} \mathrm{C}, \mathrm{k} 1(\operatorname{sim} 13)$ and $90^{\circ} \mathrm{C}, \mathrm{k} 1$ (sim 15) models were not run to $100 \%$ 630 completion, but to the point where steady state dissolution begins to roll over to asymptotic 631 slowing as seen in models $40^{\circ} \mathrm{C}, \mathrm{k} 1(\operatorname{sim} 1)$ and $40^{\circ} \mathrm{C}, \mathrm{k} 2(\operatorname{sim} 2)$. (B) Higher permeability 632 experiments and models are zoomed in to the first 100,000 seconds to show early history. Note 633 that the $75^{\circ} \mathrm{C}, \mathrm{k} 1(\operatorname{sim} 13)$ is obscured by the $40^{\circ} \mathrm{C}, \mathrm{k} 1$ experiment.

Figure 10. Results of the four experiments presented in dimensionless number space $(\mathrm{Nu}=$ 636 Nusslet number, $\mathrm{F}=$ fraction saturated, $t^{*}=$ normalized convective time). $\mathrm{Nu}$ is the ratio of the 637 experimental $\mathrm{CO}_{2}$ dissolution rate (Fig. 6) to the calculated diffusive rate. The rate curves were 638 smoothed (adjacent averaging) to reduce experimental noise. Note the four segments of the $\mathrm{Nu}$ 639 curves $(A-D)$. See text for description.

Figure 11. Zoomed in comparison of the $40^{\circ} \mathrm{C}, \mathrm{k} 1$ and $40^{\circ} \mathrm{C}, \mathrm{k} 2$ cases from Fig. 8 showing key

642 differences between the simulations and experiments. Note that the experiments show an early 643 initial rapid rise in dissolved $\mathrm{CO}_{2}$ concentration (A) that is not observed in the simulations. Also, 644 the simulations show an initial advection onset time (B) that is not seen in the experiments. 
646 Figure 12. Experiment and model comparison of the $40^{\circ} \mathrm{C}, \mathrm{k} 1$ and $\mathrm{k} 2$ cases with a time and 647 concentration shift applied to the simulations. This accounts for the early rapid dissolution seen 648 the experiments and the onset time observed in the simulations (A, B Fig. 11).

649 Figure 13. Time to reach $0.33,0.50$, and 0.66 saturation over a range of convective times $\left(t_{C}\right)$ for 650 models and experiments. The power fit for each saturation fraction is shown. Note that the 651 models are run over a much wider range of $t_{C}$ than explored by experiments. 


\subsection{References}

Backhaus, S., Turitsyn, K., Ecke, R.E., 2011. Convective instability and mass transport of diffusion layers in a Hele-Shaw geometry. Physical Review Letters 106, 104501.

657 Carman, P.C., 1937. Fluid flow through granular beds. Transactions, Institution of Chemical 658 Engineers, London 15, 150-166.

659 Crank, J., 1956. The mathematics of diffusion. Clarendon Press, Oxford.

660 Duan, Z., Hu, J., Li, D., Mao, S., 2008. Densities of the CO2-H2O and CO2-H2O-NaCl 661 systems up to $647 \mathrm{~K}$ and $100 \mathrm{MPa}$. Energy \& Fuels 22, 1666-1674.

662 Duan, Z., Sun, R., 2003. An improved model calculating CO2 solubility in pure water and

663 aqueous $\mathrm{NaCl}$ solutions from 273 to $533 \mathrm{~K}$ and from 0 to 2000 bar. Chemical Geology 193, 257664271.

665 Dullien, F.A., 1992. Porous media: fluid transport and pore structure (2nd. ed.). Academic press.

666 Emami-Meybodi, H., Hassanzadeh, H., 2013. Stability analysis of two-phase buoyancy-driven 667 flow in the presence of a capillary transition zone. Physical Review E 87, 033009.

668 Emami-Meybodi, H., Hassanzadeh, H., 2015. Two-phase convective mixing under a buoyant 669 plume of $\mathrm{CO}_{2}$ in deep saline aquifers. Advances in Water Resources 76, 55-71.

670 Emami-Meybodi, H., Hassanzadeh, H., Green, C.P., Ennis-King, J., 2015. Convective 671 dissolution of $\mathrm{CO}_{2}$ in saline aquifers: Progress in modeling and experiments. International 672 Journal of Greenhouse Gas Control 40, 238-266.

673 Ennis-King, J., Paterson, L., 2007. Coupling of geochemical reactions and convective mixing in 674 the long-term geological storage of carbon dioxide. International Journal of Greenhouse Gas 675 Control 1, 86-93.

676 Ennis-King, J., Preston, I., Paterson, L., 2005. Onset of convection in anisotropic porous media 677 subject to a rapid change in boundary conditions. Phys. Fluids 17, 084107.

678 Faisal, T.F., Chevalier, S., Bernabe, Y., Juanes, R., Sassi, M., 2015. Quantiative and qualitative 679 study of density driven $\mathrm{CO}_{2}$ mass transfer in a vertical Hele-Shaw cell. International Journal of 680 Heat and Mass Transfer 81, 901-914.

681 Farajzadeh, R., Zitha, P.L.J., Bruining, J., 2009. Enhanced mass transfer of CO2 into water: 682 experiment and modeling. Ind. Eng. Chem. Res. 48, 6423-6431.

683 Han, W.S., Lu, M., Mcpherson, B.J., Keating, E., Moore, J., Park, E., Watson, Z., Jung, N.H., 684 2013. Characteristics of CO2-driven cold-water geyser, Crystal Geyser in Utah: experimental 685 observation and mechanism analyses. Geofluids 13, 283-297. 
Hassanzadeh, H., Poolandi-Darvish, M., Keith, D.W., 2007. Scaling behavior of convective mixing, with application to geological storage of $\mathrm{CO}_{2}$. AIChE J 53, 1121-1131.

688 Jha, B., Cueto-Felgueroso, L., Juanes, R., 2011. Fluid Mixing from Viscous Fingering. Physical 689 Review Letters 106, 194502.

690 Kampman, N., Burnside, N.M., Shipton, Z.K., Chapman, H.J., Nicholl, J.A., Ellam, R.M., 691 Bickle, M.J., 2012. Pulses of carbon dioxide emissions from intracrustal faults following climatic 692 warming. Nature Geoscience 5, 352-358.

693 Keating, E.H., Newell, D.L., Dempsey, D., Pawar, R., 2014. Insights into interconnections 694 between the shallow and deep systems from a natural $\mathrm{CO}_{2}$ reservoir near Springerville, Arizona. 695 International Journal of Greenhouse Gas Control 25, 162-172.

696 Kneafsey, T.J., Pruess, K., 2010. Laboratory flow experiments for visualizing carbon dioxide697 induced, density-driven brine convection. Transport in Porous Media 82, 123-139.

698 Lenormand, R., Touboul, E., Zarcone, C., 1988. Numerical models and experiments on 699 immiscible displacements in porous media. J. Fluid Mech. 189, 165-187.

700 Lichtner, P.C., Hammond, G.E., 2012. Using high performance computing to understand roles of 701 labile and nonlabile uranium (VI) on Hanford 300 Area plume longevity. Vadose Zone Journal 702 11: 10:10.2136/vzj2011.0097.

703 Lichtner, P.C., Hammond, G.E., Lu, C., Karra, S., Bisht, G., Andre, B., Mills, R.T., Kumar, J., 704 Frederick, J.M., 2017. PFLOTRAN Users Manual, http://www.documentation.pflotran.org.

705 Linstrom, P.J., Mallard, W.G., 2012. NIST Chemistry WebBook, NIST Standard Reference

706 Database Number 69. National Institute of Standards and Technology, Gaithersburg.

707 Lu, C., Lichtner, P.C., 2007. High resolution numerical investigation on the effect of convective 708 instability on long term $\mathrm{CO}_{2}$ storage in saline aquifers. Journal of Physics: Conference Series 78, 70901042.

710 MacMinn, C.W., Szulczewski, M.L., Juanes, R., 2011. $\mathrm{CO}_{2}$ migration in saline aquifers. Part 2. 711 Capillary and solubility trapping. J. Fluid Mech. 688, 321-351.

712 Metz, B., Davidson, O., de Coninck, H., Loos, M., Meyer, L., 2005. IPCC Special Report on 713 Carbon Dioxide Capture and Storage: Prepared by Working Group III of the Intergovernmental 714 Panel on Climate Change, in: Metz, B., Davidson, O., Coninck, H., Loos, M., Meyer, L. (Eds.), 715 Cambridge, United Kingdom and New York, NY, USA, p. 442.

716 Moghaddam, R.N., Rostami, B., Pourafshary, P., 2015. Scaling analysis of the convective 717 mixing in porous media for geological storage of $\mathrm{CO}_{2}$ : An experimental approach. Chemical 718 Engineering Communications 202, 815-822. 
Moghaddam, R.N., Rostami, B., Pourafshary, P., Fallahzadeh, Y., 2012. Quanitfication of density-driven natural convection for dissolution mechanism in $\mathrm{CO}_{2}$ sequestration. Transp Porous Med 92, 439-456.

Mojtaba, S., Behzad, R., Rasoul, N.M., Mohammad, R., 2014. Experimental study of densitydriven convection effects on $\mathrm{CO}_{2}$ dissolution rate in formation water for geological storage. Journal of Natural Gas Science and Engineering 21, 600-607.

Moore, J., Adams, M., Allis, R., Lutz, S., Rauzi, S., 2005. Mineralogical and geochemical consequences of the long-term presence of $\mathrm{CO} 2$ in natural reservoirs: An example from the Springerville-St. Johns Field, Arizona, and New Mexico, U.S.A. Chemical Geology 217, 365385 .

Neufeld, J.A., Hesse, M.A., Riaz, A., Hallworth, M.A., Tchelepi, H.A., Huppert, H.E., 2010. Convective dissolution of carbon dioxide in saline aquifers. Geophysical Research Letters 37, 731 L22404.

Pau, G.S.H., Bell, J.B., Pruess, K., Almgren, A.S., Lijewski, M.J., Zhang, K., 2010. Highresolution simulation and characterization of density-driven flow in $\mathrm{CO}_{2}$ storage in saline 734 aquifers. Advances in Water Resources 33, 443-455.

Penman, H.L., 1940. Gas and vapour movements in the soil: I. The diffusion of vapours through porous solids. The Journal of Agricultural Science 30, 437-462.

Prasad, A., Simmons, C.T., 2003. Unstable density-driven flow in heterogeneous porous media: A stochastic study of the Elder [1967b] "short heater" problem. Water Resources Research 39.

Rapaka, S., Pawar, R., Stauffer, P.H., Zhang, D., Chen, S., 2009. Onset of convection over a transient base-state in anisotropic and layered porous media. J. Fluid Mech. 641, 227-244.

Riaz, A., Hesse, M., Tchelepi, H.A., Orr, F.M., 2006. Onset of convection in a gravitationally unstable diffusive boundary layer in porous media. J. Fluid Mech. 548, 87-111. supercritical carbon dioxide. High Temperature 40, 203-206.

748 Engineering Chemistry 43, 2117-2120.

749 Shipton, Z.K., Evans, J.P., Dockrill, B., Heath, J., Williams, A., Kirchner, D., Kolesar, P.T.,

750 2005. Natural leaking CO2-charged systems as analogs for failed geologic storage reservoirs, in:

751 Thomas, D.C., Benson, S.M. (Eds.), Carbon Dioxide Capture for Storage in Deep Geologic

752 Formations, Volume 2, pp. 699-712. 
753 Torquato, S., Truskett, T.M., Debenedetti, P.G., 2000. Is random close packing of spheres well 754 defined? Physical review letters 84, 2064.

755 Weissberg, H.L., 1963. Effective diffusion coefficent in porous media. Journal of Applied 756 Physics 34, 2636-2639.

757 Xu, X., Chen, S., Zhang, D., 2006. Convective stability analysis of the long-term storage of 758 carbon dioxide in deep saline aquifers. Advances in Water Resources 29, 397-407. 
stainless steel reactor placed in furnace

stainless steel access tube

water injection

\& constant $P$

DI $\mathrm{H}_{2} \mathrm{O}$

Pump

thermocouple

$\mathrm{CO}_{2}$ removed

$\mathrm{CO}_{2}$

Pump

during water injection

Reactor packed with porous media and saturated with $\mathrm{CO}_{2}$

Water injected into base diplacing $\mathrm{CO}_{2}$ 


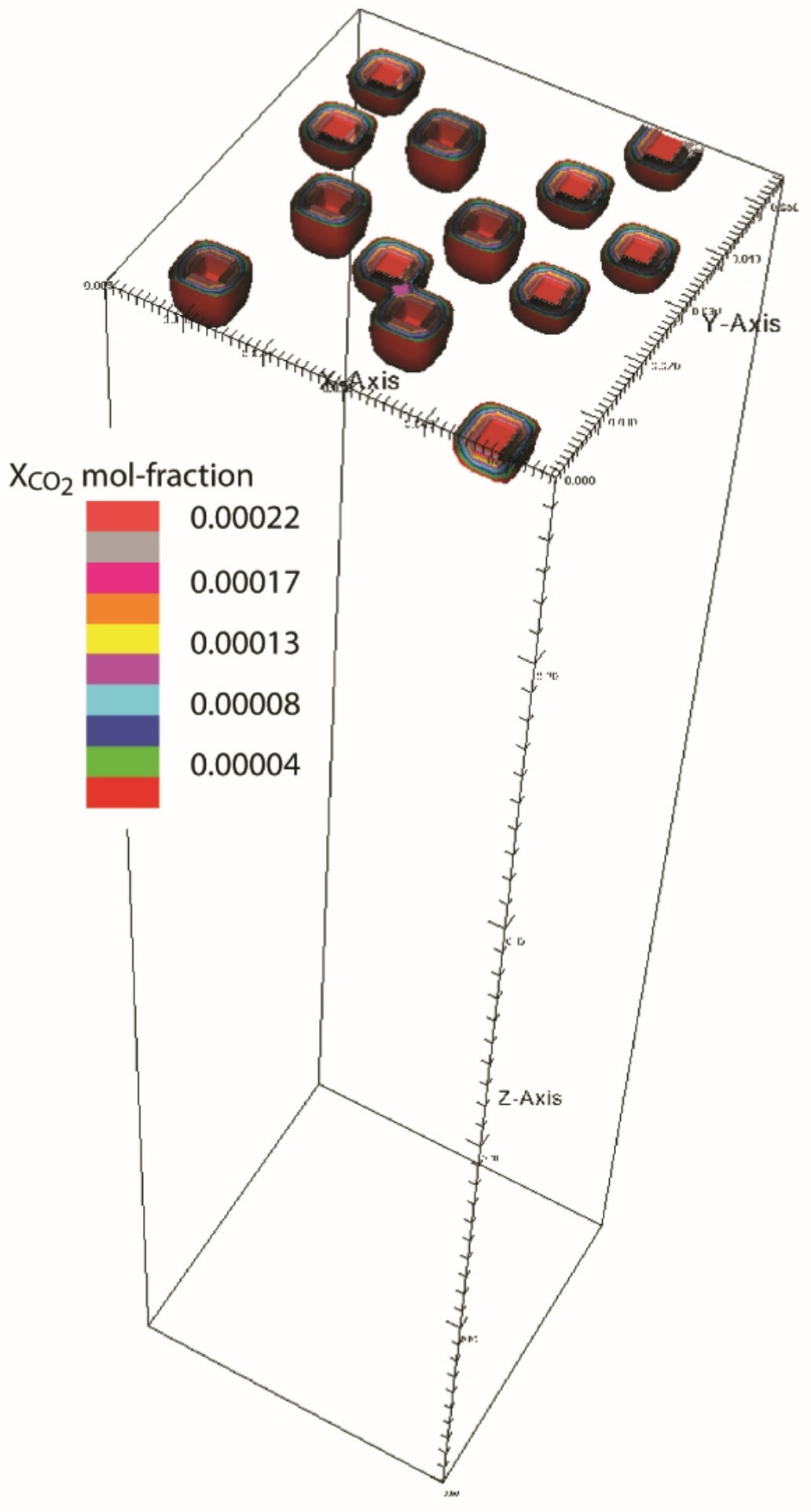




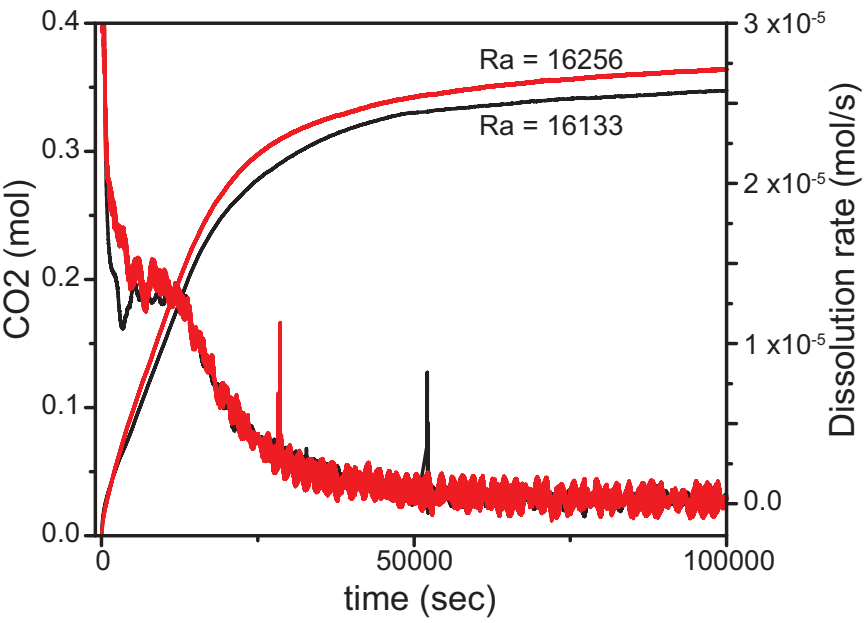




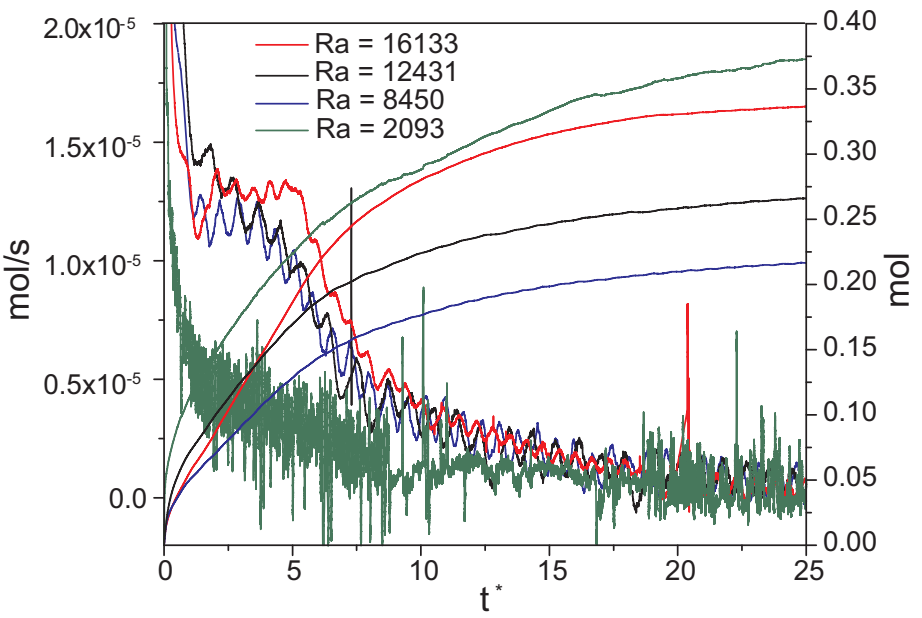





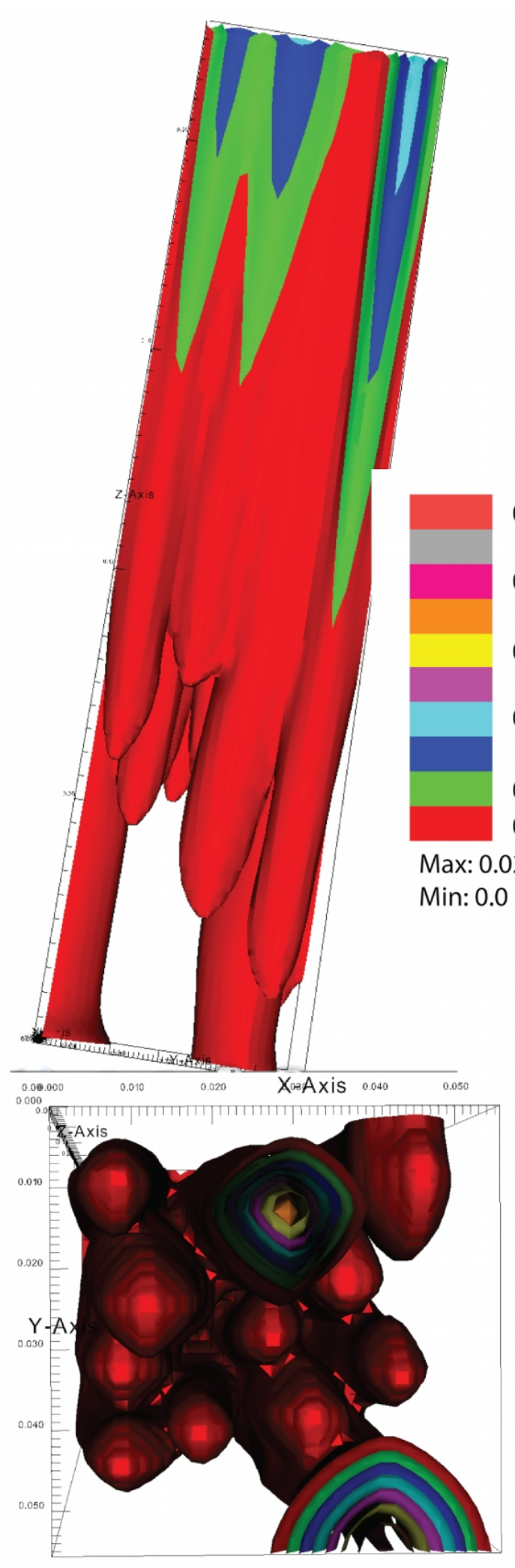

Simulation 1 (k1)
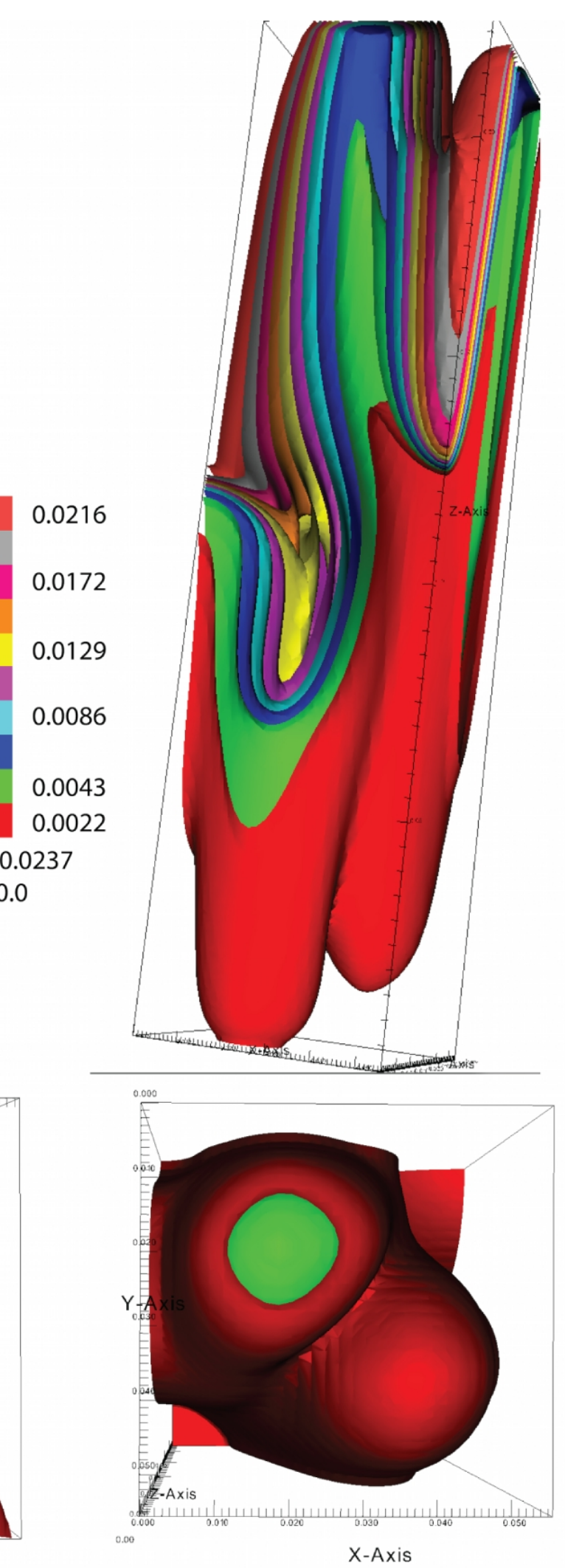

Simulation 2 (k2) 

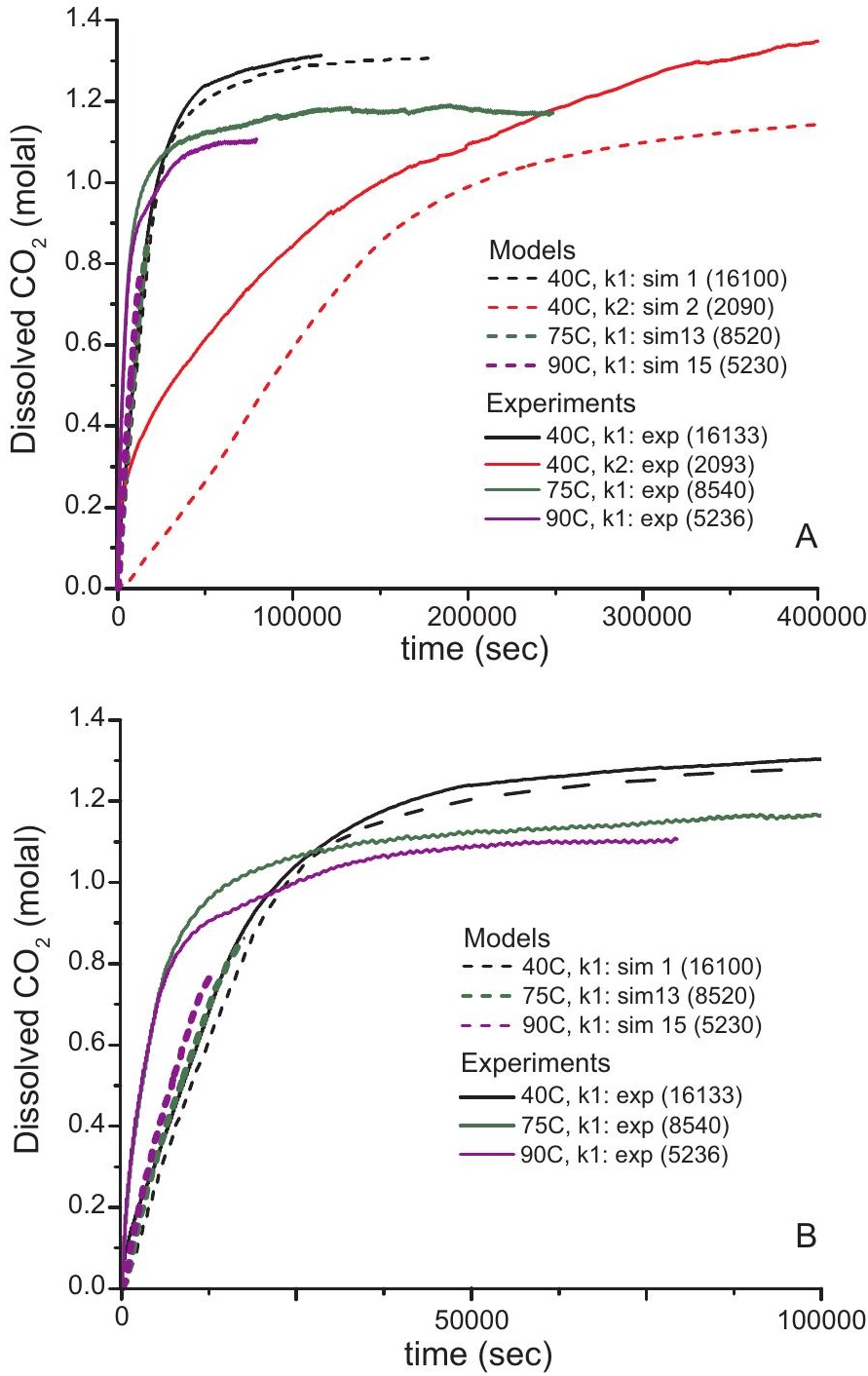


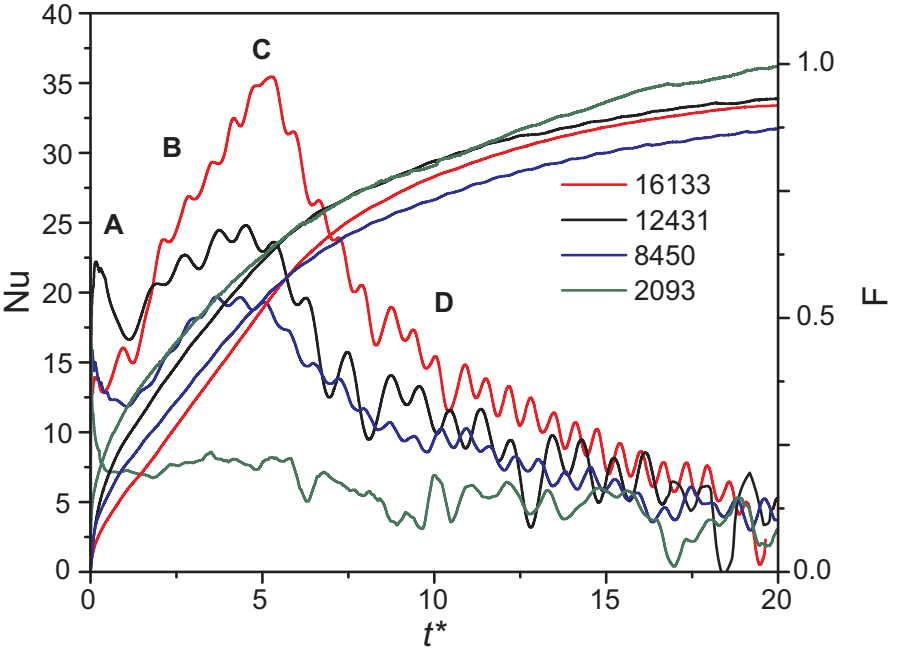




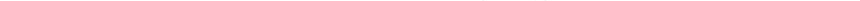




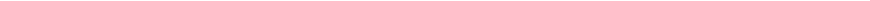




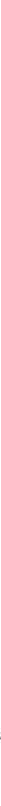




\title{
Supplemental Information
}

\section{Experimental Study of Gravitational Mixing of Supercritical $\mathrm{CO}_{2}$}

\author{
Dennis L. Newell ${ }^{1}$, J. William Carey ${ }^{2}$, Scott N. Backhaus ${ }^{3}$, and Peter Lichtner ${ }^{4}$
}

The following supplement contains Table S1 that includes the PFLOTRAN model parameters and results for the 18 simulations conducted in this study. 
Table S1. List of parameters and results from 18 numerical simulations of density-induced mixing.

\begin{tabular}{|c|c|c|c|c|c|c|c|c|c|}
\hline Simulation & 1 & 2 & 3 & 4 & 5 & 6 & 7 & 8 & 9 \\
\hline $\mathbf{T}\left({ }^{\circ} \mathrm{C}\right)$ & 40 & 40 & 40 & 40 & 40 & 40 & 40 & 40 & 40 \\
\hline$D\left(\mathrm{~m}^{2} / \mathrm{s}\right)$ & $1.00 \mathrm{E}-09$ & $1.00 \mathrm{E}-09$ & $1.00 \mathrm{E}-09$ & $1.00 \mathrm{E}-09$ & $1.00 \mathrm{E}-09$ & $1.00 \mathrm{E}-09$ & $1.00 \mathrm{E}-09$ & $1.00 \mathrm{E}-09$ & $1.00 \mathrm{E}-09$ \\
\hline$v(P a-s)$ & $6.51 \mathrm{E}-04$ & $6.51 \mathrm{E}-04$ & $6.51 \mathrm{E}-04$ & $6.51 \mathrm{E}-04$ & $6.51 \mathrm{E}-04$ & $6.51 \mathrm{E}-04$ & $6.51 \mathrm{E}-04$ & $6.51 \mathrm{E}-04$ & $6.51 \mathrm{E}-04$ \\
\hline$\rho_{\mathrm{H} 2 \mathrm{O}}\left(\mathrm{kg} / \mathrm{m}^{3}\right)$ & $1.00 \mathrm{E}+03$ & $1.00 \mathrm{E}+03$ & $1.00 \mathrm{E}+03$ & $1.00 \mathrm{E}+03$ & $1.00 \mathrm{E}+03$ & $1.00 \mathrm{E}+03$ & $1.00 \mathrm{E}+03$ & $1.00 \mathrm{E}+03$ & $1.00 \mathrm{E}+03$ \\
\hline$\rho_{\mathrm{CO} 2}\left(\mathrm{~kg} / \mathrm{m}^{3}\right)$ & $1.01 \mathrm{E}+03$ & $1.01 \mathrm{E}+03$ & $1.01 \mathrm{E}+03$ & $1.01 \mathrm{E}+03$ & $1.01 \mathrm{E}+03$ & $1.01 \mathrm{E}+03$ & $1.01 \mathrm{E}+03$ & $1.01 \mathrm{E}+03$ & $1.01 \mathrm{E}+03$ \\
\hline $\mathrm{CO}_{2}$ sat $(\mathrm{mmol} / \mathrm{kg})$ & $1.35 \mathrm{E}+03$ & $1.35 \mathrm{E}+03$ & $1.35 \mathrm{E}+03$ & $1.35 \mathrm{E}+03$ & $1.35 \mathrm{E}+03$ & $1.35 \mathrm{E}+03$ & $1.35 \mathrm{E}+03$ & $1.35 \mathrm{E}+03$ & $1.35 \mathrm{E}+03$ \\
\hline Bead dia. (m) & $5.00 \mathrm{E}-04$ & $1.80 \mathrm{E}-04$ & $5.00 \mathrm{E}-04$ & $5.00 \mathrm{E}-04$ & $5.00 \mathrm{E}-04$ & $5.00 \mathrm{E}-04$ & $1.80 \mathrm{E}-04$ & $1.80 \mathrm{E}-04$ & $1.80 \mathrm{E}-04$ \\
\hline$\phi$ & $3.67 \mathrm{E}-01$ & $3.67 \mathrm{E}-01$ & $5.00 \mathrm{E}-02$ & $1.00 \mathrm{E}-01$ & $2.00 \mathrm{E}-01$ & $2.80 \mathrm{E}-01$ & $5.00 \mathrm{E}-02$ & $1.00 \mathrm{E}-01$ & $2.00 \mathrm{E}-01$ \\
\hline$k\left(m^{2}\right)$ & $1.71 \mathrm{E}-10$ & $2.22 \mathrm{E}-11$ & $1.71 \mathrm{E}-10$ & $1.71 \mathrm{E}-10$ & $1.71 \mathrm{E}-10$ & $1.71 \mathrm{E}-10$ & $2.22 \mathrm{E}-11$ & $2.22 \mathrm{E}-11$ & $2.22 \mathrm{E}-11$ \\
\hline Depth (m) & $2.29 \mathrm{E}-01$ & $2.29 \mathrm{E}-01$ & 2.29E-01 & $2.29 \mathrm{E}-01$ & $2.29 \mathrm{E}-01$ & $2.29 \mathrm{E}-01$ & $2.29 \mathrm{E}-01$ & $2.29 \mathrm{E}-01$ & $2.29 \mathrm{E}-01$ \\
\hline Area $\left(m^{2}\right)$ & $3.09 \mathrm{E}-03$ & $3.09 \mathrm{E}-03$ & $3.09 \mathrm{E}-03$ & $3.09 \mathrm{E}-03$ & $3.09 \mathrm{E}-03$ & $3.09 \mathrm{E}-03$ & $3.09 \mathrm{E}-03$ & $3.09 \mathrm{E}-03$ & $3.09 \mathrm{E}-03$ \\
\hline $\mathbf{R a}$ & $1.61 \mathrm{E}+04$ & $2.09 \mathrm{E}+03$ & $1.18 \mathrm{E}+05$ & $5.90 \mathrm{E}+04$ & $2.95 \mathrm{E}+04$ & $2.11 \mathrm{E}+04$ & $1.53 \mathrm{E}+04$ & $7.66 \mathrm{E}+03$ & $3.83 \mathrm{E}+03$ \\
\hline$t_{\text {on }}(\mathrm{s})$ & $4.95 \mathrm{E}+01$ & $2.94 \mathrm{E}+03$ & $6.75 \mathrm{E}+00$ & $1.35 \mathrm{E}+01$ & $2.70 \mathrm{E}+01$ & $3.78 \mathrm{E}+01$ & $4.00 \mathrm{E}+02$ & $8.01 \mathrm{E}+02$ & $1.60 \mathrm{E}+03$ \\
\hline$t_{C}(\mathrm{~s})$ & $2.56 \mathrm{E}+03$ & $1.97 \mathrm{E}+04$ & $3.49 \mathrm{E}+02$ & $6.97 \mathrm{E}+02$ & $1.39 \mathrm{E}+03$ & $1.95 \mathrm{E}+03$ & $2.69 \mathrm{E}+03$ & $5.37 \mathrm{E}+03$ & $1.07 \mathrm{E}+04$ \\
\hline Rate-obs (mol/s) & $1.20 \mathrm{E}-05$ & $1.80 \mathrm{E}-06$ & $1.55 \mathrm{E}-05$ & $1.50 \mathrm{E}-05$ & $1.40 \mathrm{E}-05$ & $1.29 \mathrm{E}-05$ & $1.52 \mathrm{E}-06$ & $1.20 \mathrm{E}-06$ & $1.32 \mathrm{E}-06$ \\
\hline Onset-obs (s) & $1.98 \mathrm{E}+02$ & $4.16 \mathrm{E}+03$ & $5.04 \mathrm{E}+01$ & $4.49 \mathrm{E}+01$ & $1.12 \mathrm{E}+02$ & $1.85 \mathrm{E}+02$ & $4.27 \mathrm{E}+02$ & $8.55 \mathrm{E}+02$ & $1.77 \mathrm{E}+03$ \\
\hline Sat. at onset $(\mathrm{mol} / \mathrm{kg})$ & $1.20 \mathrm{E}-03$ & $9.60 \mathrm{E}-03$ & $0.00 \mathrm{E}+00$ & $0.00 \mathrm{E}+00$ & $0.00 \mathrm{E}+00$ & $0.00 \mathrm{E}+00$ & $0.00 \mathrm{E}+00$ & $0.00 \mathrm{E}+00$ & $4.30 \mathrm{E}-03$ \\
\hline t sat. $0.33(s)$ & $7.73 \mathrm{E}+03$ & $6.80 \mathrm{E}+04$ & $9.59 \mathrm{E}+02$ & $1.99 \mathrm{E}+03$ & $4.09 \mathrm{E}+03$ & $5.88 \mathrm{E}+03$ & $8.20 \mathrm{E}+03$ & $1.89 \mathrm{E}+04$ & 4.24E+04 \\
\hline t sat. 0.5 (s) & $1.41 \mathrm{E}+04$ & $1.12 \mathrm{E}+05$ & $1.60 \mathrm{E}+03$ & $3.31 \mathrm{E}+03$ & $6.96 \mathrm{E}+03$ & $1.04 \mathrm{E}+04$ & $1.50 \mathrm{E}+04$ & $3.36 \mathrm{E}+04$ & $6.90 \mathrm{E}+04$ \\
\hline t sat $0.66(s)$ & $2.00 \mathrm{E}+04$ & $1.65 \mathrm{E}+05$ & $2.15 \mathrm{E}+03$ & $4.56 \mathrm{E}+03$ & $1.00 \mathrm{E}+04$ & $1.51 \mathrm{E}+04$ & $2.14 \mathrm{E}+04$ & $4.76 \mathrm{E}+04$ & $8.95 \mathrm{E}+04$ \\
\hline t at bottom (s) & $7.02 \mathrm{E}+03$ & $8.57 \mathrm{E}+04$ & - & - & - & - & - & - & - \\
\hline \# fingers & 11.5 & 2.25 & - & - & - & - & - & - & - \\
\hline
\end{tabular}


Table S1 continued

\begin{tabular}{|c|c|c|c|c|c|c|c|c|c|}
\hline Simulation & 10 & 11 & 12 & 13 & 14 & 15 & 16 & 17 & 18 \\
\hline $\mathrm{T}\left({ }^{\circ} \mathrm{C}\right)$ & 40 & 40 & 40 & 75 & 75 & 90 & 90 & 40 & 40 \\
\hline$D\left(\mathrm{~m}^{2} / \mathrm{s}\right)$ & $1.00 \mathrm{E}-09$ & $1.00 \mathrm{E}-09$ & $1.00 \mathrm{E}-09$ & $2.08 \mathrm{E}-09$ & $2.08 \mathrm{E}-09$ & $2.50 \mathrm{E}-09$ & $2.50 \mathrm{E}-09$ & $1.00 \mathrm{E}-09$ & $1.00 \mathrm{E}-09$ \\
\hline$v($ Pa-s) & $6.51 \mathrm{E}-04$ & $6.51 \mathrm{E}-04$ & $6.51 \mathrm{E}-04$ & $3.74 \mathrm{E}-04$ & $3.74 \mathrm{E}-04$ & $3.10 \mathrm{E}-04$ & $3.10 \mathrm{E}-04$ & $6.51 \mathrm{E}-04$ & $6.51 \mathrm{E}-04$ \\
\hline$\rho_{\mathrm{H} 2 \mathrm{O}}\left(\mathrm{kg} / \mathrm{m}^{3}\right)$ & $1.00 \mathrm{E}+03$ & $1.00 \mathrm{E}+03$ & $1.00 \mathrm{E}+03$ & $9.83 \mathrm{E}+02$ & $9.83 \mathrm{E}+02$ & $9.74 \mathrm{E}+02$ & $9.74 \mathrm{E}+02$ & $1.00 \mathrm{E}+03$ & $1.00 \mathrm{E}+03$ \\
\hline$\rho_{\mathrm{CO} 2}\left(\mathrm{~kg} / \mathrm{m}^{3}\right)$ & $1.01 \mathrm{E}+03$ & $1.01 \mathrm{E}+03$ & $1.01 \mathrm{E}+03$ & $9.92 \mathrm{E}+02$ & $9.92 \mathrm{E}+02$ & $9.81 \mathrm{E}+02$ & $9.81 \mathrm{E}+02$ & $1.01 \mathrm{E}+03$ & $1.01 \mathrm{E}+03$ \\
\hline $\mathrm{CO}_{2}$ sat $(\mathrm{mmol} / \mathrm{kg})$ & $1.35 \mathrm{E}+03$ & $1.35 \mathrm{E}+03$ & $1.35 \mathrm{E}+03$ & $1.18 \mathrm{E}+03$ & $1.18 \mathrm{E}+03$ & $1.10 \mathrm{E}+03$ & $1.10 \mathrm{E}+03$ & $1.35 \mathrm{E}+03$ & $1.35 \mathrm{E}+03$ \\
\hline Bead dia. (m) & $5.0 \mathrm{E}-04$ & NA & NA & $5.0 \mathrm{E}-04$ & $1.8 \mathrm{E}-04$ & $5.0 \mathrm{E}-04$ & $1.8 \mathrm{E}-04$ & NA & NA \\
\hline$\phi$ & $3.67 \mathrm{E}-01$ & $3.67 \mathrm{E}-01$ & $3.67 \mathrm{E}-01$ & $3.67 \mathrm{E}-01$ & $3.67 \mathrm{E}-01$ & $3.67 \mathrm{E}-01$ & $3.67 \mathrm{E}-01$ & $3.67 \mathrm{E}-01$ & $3.67 \mathrm{E}-01$ \\
\hline $\mathbf{k}\left(\mathrm{m}^{2}\right)$ & $1.71 \mathrm{E}-10$ & $9.00 \mathrm{E}-11$ & $6.0 \mathrm{E}-10$ & $1.71 \mathrm{E}-10$ & $2.22 \mathrm{E}-11$ & $1.71 \mathrm{E}-10$ & $2.22 \mathrm{E}-11$ & $5.00 \mathrm{E}-12$ & $5.00 \mathrm{E}-12$ \\
\hline Depth (m) & $4.59 \mathrm{E}-01$ & 2.29E-01 & 2.29E-01 & $1.76 \mathrm{E}-01$ & $1.76 \mathrm{E}-01$ & $1.36 \mathrm{E}-01$ & $1.36 \mathrm{E}-01$ & 2.29E-01 & $2.29 \mathrm{E}+00$ \\
\hline $\operatorname{Area}\left(m^{2}\right)$ & 3.09E-03 & 3.09E-03 & 3.09E-03 & 3.09E-03 & 3.09E-03 & 3.09E-03 & 3.09E-03 & 3.09E-03 & $3.09 \mathrm{E}-03$ \\
\hline $\mathbf{R a}$ & $3.21 \mathrm{E}+04$ & $8.44 \mathrm{E}+03$ & $5.63 \mathrm{E}+04$ & $8.52 \mathrm{E}+03$ & $1.11 \mathrm{E}+03$ & $5.23 \mathrm{E}+03$ & $6.78 \mathrm{E}+02$ & $4.70 \mathrm{E}+02$ & $4.70 \mathrm{E}+03$ \\
\hline$t_{\text {on }}(\mathrm{s})$ & $4.95 \mathrm{E}+01$ & $1.79 \mathrm{E}+02$ & $4.02 \mathrm{E}+00$ & $8.14 \mathrm{E}+01$ & $4.83 \mathrm{E}+03$ & $1.08 \mathrm{E}+02$ & $6.38 \mathrm{E}+03$ & $5.79 \mathrm{E}+04$ & $5.79 \mathrm{E}+04$ \\
\hline$t_{C}(\mathbf{s})$ & - & $4.86 \mathrm{E}+03$ & $7.29 \mathrm{E}+02$ & $1.74 \mathrm{E}+03$ & $1.34 \mathrm{E}+04$ & $1.41 \mathrm{E}+03$ & $1.09 \mathrm{E}+04$ & $8.75 \mathrm{E}+04$ & $8.75 \mathrm{E}+05$ \\
\hline Rate-obs (mol/s) & - & $5.08 \mathrm{E}-06$ & $5.29 \mathrm{E}-05$ & $1.02 \mathrm{E}-05$ & $1.03 \mathrm{E}-06$ & $9.51 \mathrm{E}-06$ & $1.13 \mathrm{E}-06$ & $9.20 \mathrm{E}-08$ & $2.50 \mathrm{E}-07$ \\
\hline Onset-obs (s) & - & $5.33 \mathrm{E}+02$ & $6.48 \mathrm{E}+00$ & $1.94 \mathrm{E}+02$ & $6.81 \mathrm{E}+03$ & $1.94 \mathrm{E}+02$ & $9.25 \mathrm{E}+03$ & $1.23 \mathrm{E}+05$ & $2.26 \mathrm{E}+05$ \\
\hline Sat. at onset $(\mathrm{mol} / \mathbf{k g})$ & - & $3.20 \mathrm{E}-03$ & $5.00 \mathrm{E}-04$ & $1.00 \mathrm{E}-03$ & $2.20 \mathrm{E}-02$ & $1.00 \mathrm{E}-03$ & $3.70 \mathrm{E}-02$ & $5.37 \mathrm{E}-02$ & $5.00 \mathrm{E}-03$ \\
\hline t sat. $0.33(s)$ & - & $1.65 \mathrm{E}+04$ & $2.10 \mathrm{E}+03$ & $5.44 \mathrm{E}+03$ & $5.44 \mathrm{E}+04$ & $4.14 \mathrm{E}+03$ & $4.02 \mathrm{E}+04$ & $4.43 \mathrm{E}+05$ & $3.03 \mathrm{E}+06$ \\
\hline t sat. $0.5(s)$ & - & $2.97 \mathrm{E}+04$ & $3.51 \mathrm{E}+03$ & $1.04 \mathrm{E}+04$ & $9.97 \mathrm{E}+04$ & $8.00 \mathrm{E}+03$ & $6.79 \mathrm{E}+04$ & $9.83 \mathrm{E}+05$ & $9.79 \mathrm{E}+06$ \\
\hline t sat $0.66(s)$ & - & $4.19 \mathrm{E}+04$ & $4.83 \mathrm{E}+03$ & $1.51 \mathrm{E}+04$ & $1.32 \mathrm{E}+05$ & $1.18 \mathrm{E}+04$ & $9.15 \mathrm{E}+04$ & $1.17 \mathrm{E}+06$ & $3.77 \mathrm{E}+08$ \\
\hline t at bottom (s) & - & $1.42 \mathrm{E}+04$ & $1.66 \mathrm{E}+03$ & - & - & - & - & - & - \\
\hline \# fingers & - & 7 & 11 & - & - & - & - & - & - \\
\hline
\end{tabular}

